\title{
A126 in the active site and TI167/168 in the TI loop are essential determinants of the substrate specificity of PTEN
}

\author{
Michael G. Leitner ${ }^{1,2}$ (1) $\cdot$ Kirstin Hobiger $^{1} \cdot$ Angeliki Mavrantoni $^{1} \cdot$ Anja Feuer $^{1} \cdot$ Johannes Oberwinkler $^{1}$. \\ Dominik Oliver ${ }^{1,3,4} \cdot$ Christian R. Halaszovich ${ }^{1}$
}

Received: 11 October 2017 / Revised: 19 June 2018 / Accepted: 3 July 2018 / Published online: 9 July 2018

(c) The Author(s) 2018

\begin{abstract}
PTEN prevents tumor genesis by antagonizing the PI3 kinase/Akt pathway through D3 site phosphatase activity toward $\mathrm{PI}(3,4) \mathrm{P}_{2}$ and $\mathrm{PI}(3,4,5) \mathrm{P}_{3}$. The structural determinants of this important specificity remain unknown. Interestingly, PTEN shares remarkable homology to voltage-sensitive phosphatases (VSPs) that dephosphorylate D5 and D3 sites of PI $(4,5) \mathrm{P}_{2}$, $\mathrm{PI}(3,4) \mathrm{P}_{2}$, and $\mathrm{PI}(3,4,5) \mathrm{P}_{3}$. Since the catalytic center of PTEN and VSPs differ markedly only in TI/gating loop and active site motif, we wondered whether these differences explained the variation of their substrate specificity. Therefore, we introduced mutations into PTEN to mimic corresponding sequences of VSPs and studied phosphatase activity in living cells utilizing engineered, voltage switchable PTEN $\mathrm{Civ}_{\mathrm{C}}$, a Ci-VSP/PTEN chimera that retains D3 site activity of the native enzyme. Substrate specificity of this enzyme was analyzed with whole-cell patch clamp in combination with total internal reflection fluores-

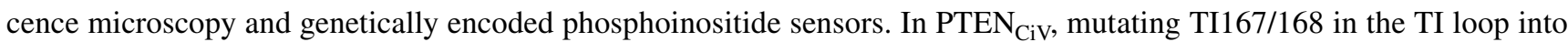
the corresponding ET pair of VSPs induced VSP-like D5 phosphatase activity toward $\mathrm{PI}(3,4,5) \mathrm{P}_{3}$, but not toward $\mathrm{PI}(4,5) \mathrm{P}_{2}$. Combining TI/ET mutations with an A126G exchange in the active site removed major sequence variations between PTEN and VSPs and resulted in D5 activity toward $\mathrm{PI}(4,5) \mathrm{P}_{2}$ and $\mathrm{PI}(3,4,5) \mathrm{P}_{3}$ of $\mathrm{PTEN}_{\mathrm{CiV}}$. This PTEN mutant thus fully reproduced the substrate specificity of native VSPs. Importantly, the same combination of mutations also induced D5 activity toward $\mathrm{PI}(3,4,5) \mathrm{P}_{3}$ in native PTEN demonstrating that the same residues determine the substrate specificity of the tumor suppressor in living cells. Reciprocal mutations in VSPs did not alter their substrate specificity, but reduced phosphatase activity. In summary, A126 in the active site and TI167/168 in the TI loop are essential determinants of PTEN's substrate specificity, whereas additional features might contribute to the enzymatic activity of VSPs.
\end{abstract}

Keywords Voltage-sensitive phosphatases · Protein tyrosine phosphatases (PTPs) · Ci-VSP · Hs-VSP · Neomorphic mutations $\cdot$ Phosphoinositides $\cdot$ Phosphoinositide signaling

Michael G. Leitner and Kirstin Hobiger contributed equally to this work.

Electronic supplementary material The online version of this article (https://doi.org/10.1007/s00018-018-2867-z) contains supplementary material, which is available to authorized users.

Christian R. Halaszovich

christian.halaszovich@staff.uni-marburg.de

1 Institute of Physiology and Pathophysiology, PhilippsUniversity Marburg, Deutschhausstr. 1-2, 35037 Marburg, Germany

2 Division of Physiology, Department of Physiology and Medical Physics, Medical University of Innsbruck, 6020 Innsbruck, Austria

\section{Introduction}

PTEN (phosphatase and tensin homologue deleted on chromosome 10) is a well-characterized D3-phosphoinositide (PI) phosphatase that dephosphorylates $\mathrm{PI}(3,4) \mathrm{P}_{2}$ and $\mathrm{PI}(3,4,5) \mathrm{P}_{3}$ to $\mathrm{PI}(4) \mathrm{P}$ and $\mathrm{PI}(4,5) \mathrm{P}_{2}$, respectively [1-6]. In

3 DFG Research Training Group GRK 2213, Membrane Plasticity in Tissue Development and Remodeling, Philipps-University Marburg, 35043 Marburg, Germany

4 Center for Mind, Brain and Behavior (CMBB), Universities of Marburg and Giessen, Marburg/Giessen, Germany 
doing so, PTEN prevents tumorigenesis by antagonizing growth factor-stimulated phosphoinositide 3-kinases (PI3K) $[2,7]$. Importance of PTEN is highlighted by the fact that various PTEN mutations were found in numerous tumors [6, $8,9]$, but also in epilepsy [10], autism spectrum disorders [11-15], and Alzheimer's disease [16, 17]. Despite physiological relevance, little is known about the structural origin for this catalytic specificity.

Interestingly, PTEN shows high sequence similarity to the catalytic domain (CD) of voltage-sensitive phosphatases (VSPs; Fig. S1), such as CiVSP [18], Dr-VSP [19], Xl-VSP1 and Xl-VSP2 [20], and the human orthologue Hs-VSP1 (previously named hVSP1, TPTE2 or TPIP) [21-23]. VSPs are controlled by membrane voltage, such that depolarization increases phosphatase activity. The enzymatic activity of Ci-VSP [24, 25] and Hs-VSP1 [23, 26] has been characterized in living cells, identifying them as $\mathrm{PI}(4,5) \mathrm{P}_{2}$ and $\mathrm{PI}(3,4,5) \mathrm{P}_{3}$ D5-phosphatases. Data on Xl-VSP1 and Xl-VSP2 [20] and Dr-VSP [19] gave further evidence for D5-phosphatase activity toward $\mathrm{PI}(4,5) \mathrm{P}_{2}$ of VSPs in general. However, recent data expanded the initial concept of VSPs being pure D5 site-specific phosphatases, since D3 activity toward $\mathrm{PI}(3,4) \mathrm{P}_{2}$ and $\mathrm{PI}(3,4,5) \mathrm{P}_{3}$ was revealed for Ci-VSP [26-30]. These findings indicate less specific activity of VSPs compared to the highly specific D3 phosphatase PTEN. Given high sequential and structural homology

A

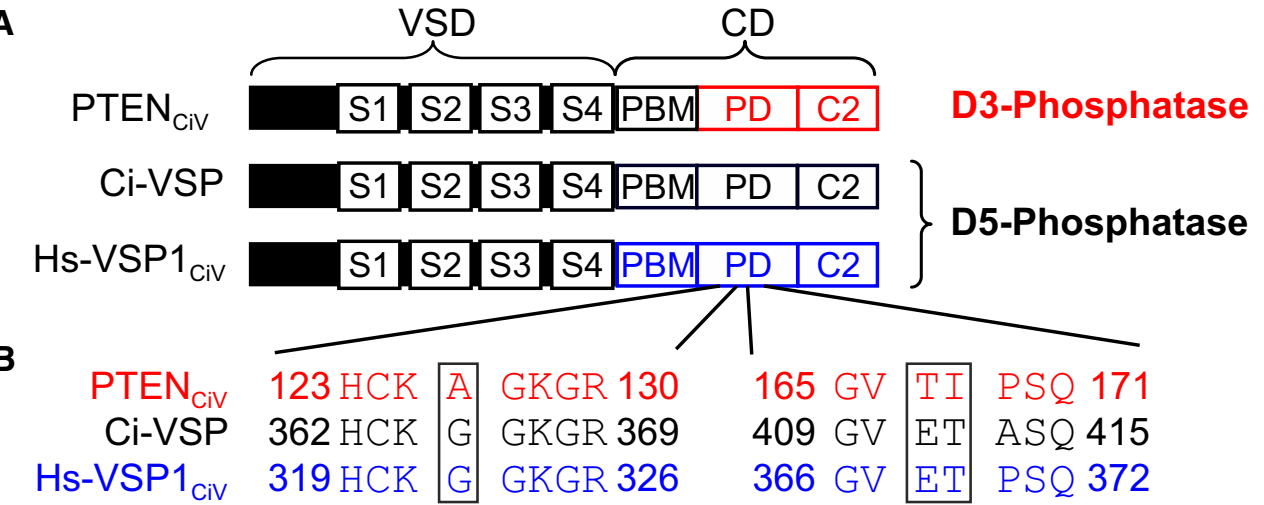

C

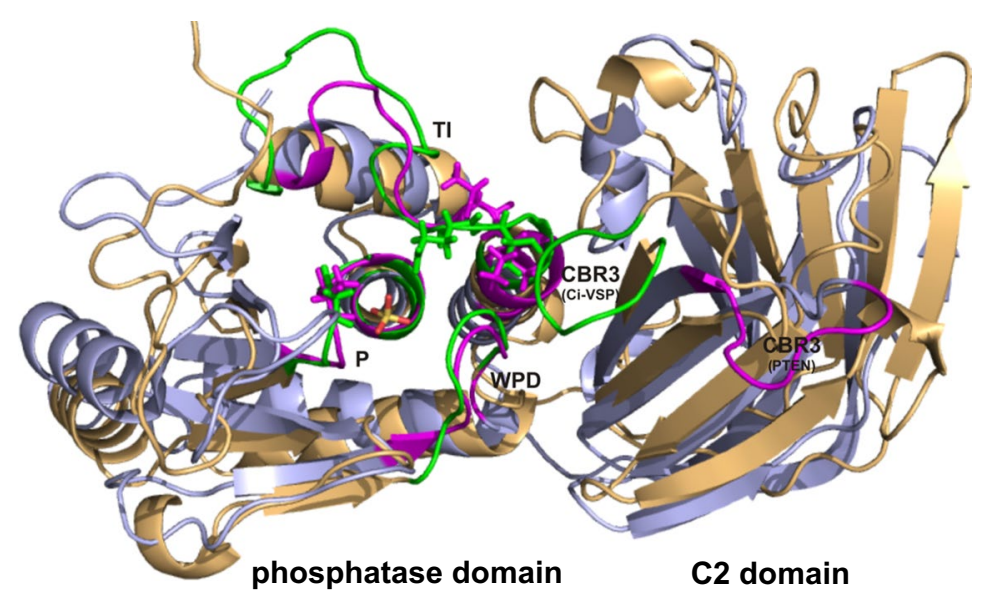

Fig. 1 Schematic representation and structural alignment of engineered voltage-sensitive phosphatases. a Schematic representation of the VSPs used in this study. The chimeras consist of the N-terminal voltage-sensor domain (VSD) of Ci-VSP and the C-terminal catalytic domain (CD) of PTEN or Hs-VSP1 (S1-S4, transmembrane domains; PBM, phospholipid-binding motif; PD, phosphatase domain; C2, C2 domain). b Sequence alignment of $\mathrm{P}$ loop $\left(\mathrm{HCX}_{5} \mathrm{R}\right.$ - or active site motif) and TI loop (PTEN)/gating loop (Ci-VSP and Hs-VSP1 $1_{\mathrm{CiV}}$ ). Note that sequence differences between the D3-site phosphatase PTEN $_{\mathrm{CiV}}$ and the D5-site phosphatases Ci-VSP and Hs-VSP1 $1_{\mathrm{CiV}}$ are restricted to A126 in PTEN corresponding to G365 in Ci-VSP and
G322 in Hs-VSP1, and to TI167/168 in PTEN that is ET411/412 in Ci-VSP and ET368/369 in Hs-VSP1. c Structural alignment of PTEN (in blue; PDB 1d5r [32]) and the catalytic domain of Ci-VSP (in orange; homology model based on molecular dynamics simulations as described earlier [36]) with a phosphate ion bound to the active site. Flexible motifs shaping the substrate binding pocket (P, TI and WPD loop) and the CBR3 loop of the C2 domain are highlighted in green and magenta for Ci-VSP and PTEN, respectively. The A/G position in the $\mathrm{P}$ loop and the TI/ET pair in the TI/gating loop are depicted as sticks 
of VSPs and PTEN (Fig. 1), the variation in their substrate specificity is surprising and raises the question of the structural origin of this difference.

PTEN and VSPs belong to the protein tyrosine phosphatase (PTP) superfamily due to the $\mathrm{HCX}_{5} \mathrm{R}$ motif in their active site (called "PTP recognition" or "P loop"). These enzymes share canonical structural properties in the phosphatase domain, with three loops forming the substrate binding pocket (Fig. 1) [8, 31]. Structural data available for PTEN [32, 33] and Ci-VSP [27, 34] indicated that $\mathrm{P}$ loop and two other motifs (the TI/gating and the WPD loop), which surround the active site (Fig. 1c), dynamically shape the size and depth of the substrate binding pocket. Therefore, residues within these loops might play a crucial role in determining the substrate specificity of these phosphatases. Indeed, amino acids lining the active site pocket of PTEN differ significantly only in two places from those found in VSPs: (i) in the $\mathrm{HCX}_{5} \mathrm{R}$ motif of the $\mathrm{P}$ loop, and (ii) in the TI/gating loop (Fig. 1b, Fig. S1).

(i) The P loop sequences of PTEN and VSPs vary in only one position. Where PTEN contains an alanine (A126), VSPs carry a glycine at the homologous position (Fig. 1b). Recently, we found that the A126G mutation shifted the specificity of PTEN from $\mathrm{D} 3$ to $\mathrm{D} 5$ site activity toward $\mathrm{PI}(3,4,5) \mathrm{P}_{3}[35]$. Interestingly, this gain-of-function mutation stimulated the PI3K/Akt proliferation pathway and potential tumor growth in a prostate cancer patient [35]. As PTEN(A126G) did not recognize $\mathrm{PI}(4,5) \mathrm{P}_{2}$ as substrate, the single amino acid exchange in the $\mathrm{P}$ loop is sufficient to alter site specificity, but not substrate specificity of PTEN. It has already been speculated that the homologous exchange of glycine to alanine (G/A mutations) in Ci-VSP converts its pre-dominant D5 activity into activity towards the D3 site [24]. However, respective results on VSP mutants obtained in different cell types and in vitro are inconsistent $[23,27]$ and thus need further clarification.

(ii) The so-called "TI loop" (named after the threonine/ isoleucine pair in PTEN; also called "gating loop" in VSPs) differs in length and sequence between PTEN and VSPs (Fig. S1). In particular, the TI pair in PTEN is replaced by glutamic acid/threonine (ET) in the corresponding loop of VSPs. The TI/gating loop was already proposed to interfere with enzymatic activity in both phosphatases [27, 32, 34, 36]. Based on crystallography data of the soluble catalytic domain of Ci-VSP, it was suggested that the glutamate at position 411 regulates access for the substrate to the active site and, therefore, might interfere with substrate specificity [27, 34]. Importantly, however, the molecular mechanism behind this regulation is not fully understood.

Since available structural data do not provide a satisfying explanation for the relevance of residues in the $\mathrm{P}$ and TI loop, we aimed at clarifying their role for determining the substrate specificity of the phosphatases. For this, we employed well-characterized Ci-VSP and engineered chimeric voltage-sensitive enzymes $\mathrm{PTEN}_{\mathrm{CiV}}$ (originally named "Ci-VSPTEN16") [37] and Hs-VSP1 $1_{\mathrm{CiV}}$ [23]. In these chimeric proteins, the $\mathrm{CD}$ of $\mathrm{Ci}-\mathrm{VSP}$ was replaced by that of PTEN or Hs-VSP1 enabling direct control of phosphatase activity by membrane voltage while retaining the substrate specificity of the native enzymes [23, 37].

We performed systematic step-by-step exchanges of amino acids in the $\mathrm{P}$ and the TI/gating loop of PTEN $\mathrm{CiV}_{\mathrm{C}}$ into corresponding residues of VSPs and vice versa. Substrate specificity and enzymatic activity of the phosphatases were measured using the whole-cell patch clamp technique combined with total internal reflection fluorescence (TIRF) microscopy in living cells. We found that alanine at position 126 in the $\mathrm{P}$ loop and the TI pair in the TI loop independently determine substrate specificity of PTEN $_{\mathrm{CiV}}$ : exchanging these amino acids individually to corresponding residues of VSPs conferred VSP-like D5 activity toward $\mathrm{PI}(3,4,5) \mathrm{P}_{3}$ to otherwise $\mathrm{D} 3$ site-specific PTEN $_{\mathrm{CiV}}$, although the phosphatase remained inactive toward $\mathrm{PI}(4,5) \mathrm{P}_{2}$. Strikingly, the simultaneous exchange in both loops, which removed major sequence differences between VSPs and PTEN, completely converted PTEN into a D5 phosphatase with the apparent substrate specificity of native VSPs. In contrast, reciprocal mutations in VSPs reduced or even abolished phosphatase activity indicating the existence of a distinct mechanism for substrate specificity in these enzymes.

\section{Materials and methods}

\section{Molecular biology}

The construction of chimeras containing the VSD of Ci-VSP and the cytosolic domains of either PTEN or Hs-VSP1 was described elsewhere [23, 37]. Hs-VSP1 $1_{\mathrm{CiV}}(\mathrm{D} 136 \mathrm{~N})$ was used in all experiments (termed here as "Hs-VSP1 $1_{\mathrm{CiV}}$ "), since the voltage dependence of this mutant is comparable to that of Ci-VSP [23]. Point mutations were introduced by site-directed mutagenesis. All cDNA sequences were verified before use (Seqlab Laboratories, Göttingen, Germany). Throughout the manuscript, the term "wild type" denotes absence of mutations in the catalytic domain, also with respect to the chimeric enzymes. 


\section{Cell culture and expression of proteins of interest}

Chinese hamster ovary $(\mathrm{CHO})$ cells were grown as described before [25], plated onto glass bottom dishes (WillCo Wells B. V., Amsterdam, The Netherlands) or cover slips, and transfected using jetPEI (Polyplus Transfection, Illkirch, France). Madin-Darby Canine Kidney (MDCK) cells were grown in DMEM GlutaMax (Gibco/ThermoFisher Scientific, Darmstadt, Germany), supplemented with $10 \%$ (vol/ vol) FBS and 1\% (vol/vol) Pen/Strep. MDCK cells were seeded on cover slips in $35 \mathrm{~mm}$ diameter cell culture dishes and transfected using Lipofectamine 2000 (ThermoFisher Scientific). PC-3 cells were grown as described before [35], seeded in 35-60 mm diameter cell culture dishes and transfected using jetPET (Polyplus Transfection). Expression vectors used for transfection were: PLC $\delta_{1}-\mathrm{PH}$ (UniProt accession number P51178), and Btk-PH (Q06187) in pEGFP-N1 vector; TAPP1-PH (Q9HB21) in FUGW vector (contains eGFP); bovine phosphatidylinositol 3-kinase p110 $\alpha$ (constitutively active mutant K227E; P32871) [38]; Ci-VSP (Q4W8A1) or chimeras in pmRFP-C1 vector; KCNQ2 $\left(\mathrm{K}_{\mathrm{v}} 7.2\right)(\mathrm{O} 43526)$ in $\mathrm{pBK}-\mathrm{CMV}$. For confocal imaging and $\mathrm{PI}(3,4) \mathrm{P}_{2}$ mass ELISA, non-chimeric human PTEN wild type (P60484) or mutated PTEN were cloned in the pmRFP$\mathrm{C} 1$ vector. All experiments were performed $24-48 \mathrm{~h}$ after transfection.

\section{Electrophysiology}

In TIRF experiments, the whole-cell configuration of the patch clamp technique was employed using an EPC-10 amplifier (HEKA Elektronik, Lambrecht Germany) controlled by PatchMaster software (HEKA) on a Mac mini (Apple Inc, Cupertino, CA, USA). Cells were clamped to $-60 \mathrm{mV}$ and phosphatases were activated by depolarizing the membrane potential to $+80 \mathrm{mV}$. In these experiments, series resistance $\left(R_{\mathrm{s}}\right)$ typically was below $5 \mathrm{M} \Omega$ and no $R_{\mathrm{s}}$ compensation was applied.

$\mathrm{KCNQ} 2\left(\mathrm{~K}_{\mathrm{v}} 7.2\right)$ currents were recorded in the whole-cell configuration with an AxoPatch 200B amplifier (Molecular Devices, Sunnyvale, CA, USA) in conjunction with an ITC18 interface (HEKA) controlled by PatchMaster software on a PC running Microsoft Windows. Currents were sampled at $5 \mathrm{kHz}$ and low-pass filtered at $2 \mathrm{kHz}$. $R_{\mathrm{s}}$ was typically below $6 \mathrm{M} \Omega$ and was compensated throughout the recordings (80-90\%). KCNQ2 currents were elicited by a voltage step from the holding potential of -60 to $0 \mathrm{mV}$ every $5 \mathrm{~s}$ and phosphatases were activated at $+80 \mathrm{mV}$ in between these steps. Data were analyzed using PatchMaster (HEKA) and IgorPro (Wavemetrics, Lake Oswego, OR, USA).

Patch pipettes were pulled from borosilicate glass using a P2000 puller (Sutter Instrument Company, Novato, CA, USA) and had an open pipette resistance between 2 and
$4 \mathrm{M} \Omega$ after back-filling with intracellular solution containing (in mM) $135 \mathrm{KCl}, 2.41 \mathrm{CaCl}_{2}\left(100 \mathrm{nM}\right.$ free $\left.\mathrm{Ca}^{2+}\right), 3.5$ $\mathrm{MgCl}_{2}, 5$ EGTA, 5 HEPES and $2.5 \mathrm{Na}_{2}$-ATP, pH 7.3 (with $\mathrm{KOH}), 290-295 \mathrm{mOsm} / \mathrm{kg}$. Throughout the recordings, cells were kept in extracellular solution containing (in $\mathrm{mM}$ ) $144 \mathrm{NaCl}, 5.8 \mathrm{KCl}, 0.9 \mathrm{MgCl}_{2}, 1.3 \mathrm{CaCl}_{2}, 0.7 \mathrm{NaH}_{2} \mathrm{PO}_{4}$, 5.6 D-glucose, and 10 HEPES, pH 7.4 (with $\mathrm{NaOH}$ ), $305-310 \mathrm{mOsm} / \mathrm{kg}$. All experiments were performed at room temperature $\left(22-25^{\circ} \mathrm{C}\right)$.

\section{TIRF imaging}

The majority of TIRF experiments were performed using an upright TIRF setup, as described before [25]. Briefly, a BX51WI upright microscope (Olympus) equipped with a TIRF condenser (NA 1.45; Olympus) and a $488 \mathrm{~nm}$ laser (20 mW; Picarro, Sunnyvale, CA, USA) was used. Fluorescence was imaged through a LUMPlanFI/IR $40 \times / 0.8$ NA water immersion objective. Images were acquired with a TILL-Imago QE cooled CCD camera (TILL photonics, Gräfelfing, Germany) in combination with a Polychrom IV light source (TILL photonics) controlled by TILLvision software (TILL photonics). The laser shutter was controlled by the Polychrom IV.

For experiments shown in Fig. 2a, an inverted TIRF setup was used. A Nikon Eclipse Ti inverted microscope was equipped with an Apo TIRF 100×/1.49 oil immersion objective, a TIRF condenser (Rapp OptoElectronic, Wedel, Germany) and a $488 \mathrm{~nm}$ laser (200 mW, iBeam smart; Toptica Photonics AG, Gräfelfing, Germany). Images were acquired with a CoolSnap HQ2 camera (Photometrics, Tuscon, AZ, USA). The laser shutter (nmLaser Products Inc., San José, CA, USA) was controlled by the camera. Image acquisition was performed using the $\mu$-Manager software [39].

For all TIRF experiments, the frame interval was $3 \mathrm{~s}$ and the electrophysiology setup was synchronized to the imaging setup. Cells were co-transfected with plasmids encoding a mRFP-tagged phosphatase, a PI sensor domain, and-in case of the $\mathrm{PI}(3,4) \mathrm{P}_{2}$ or $\mathrm{PI}(3,4,5) \mathrm{P}_{3}$ binding domains-additionally with constitutively active PI3-kinase p110 $\alpha$ (K227E) [38]. Experiments were done $24-48 \mathrm{~h}$ post-transfection on cells selected for co-expression of the mRFP-tagged phosphatase and the GFP-tagged PI sensor probe. Cells under investigation were whole-cell patch clamped as described above. Experiments were carried out at room temperature $\left(22-25{ }^{\circ} \mathrm{C}\right)$. Imaging data were analyzed using TILLvision (Till photonics), ImageJ/Fiji (NIH, Bethesda) [40, 41], and IgorPro (Wavemetrics). Regions of interest (ROIs) encompassed the footprint of a single cell excluding cell margins to avoid movement artifacts. $F / F_{0}$ traces were calculated from the background-corrected TIRF signal intensity $F$, normalized to the initial intensity $F_{0}$, which was calculated as the average over the baseline interval, by averaging over the 
A

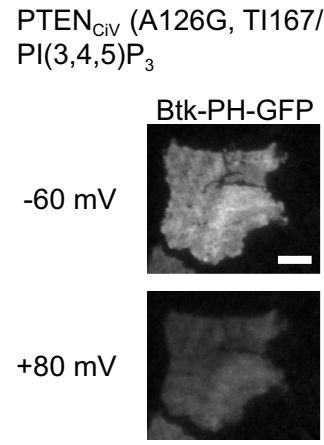

$$
\text { BET) }
$$

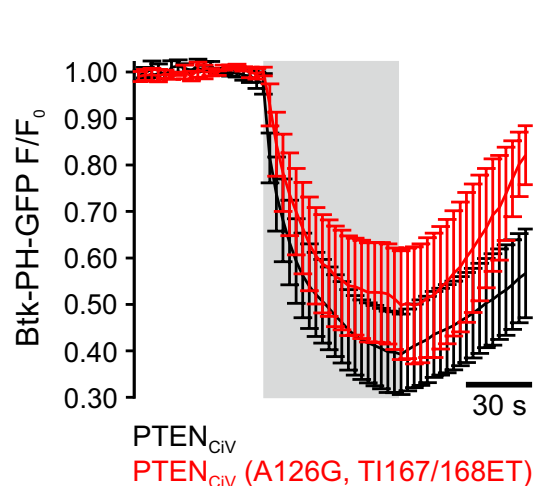

B

Ci-VSP

$\mathrm{Pl}(3,4,5) \mathrm{P}_{3}$

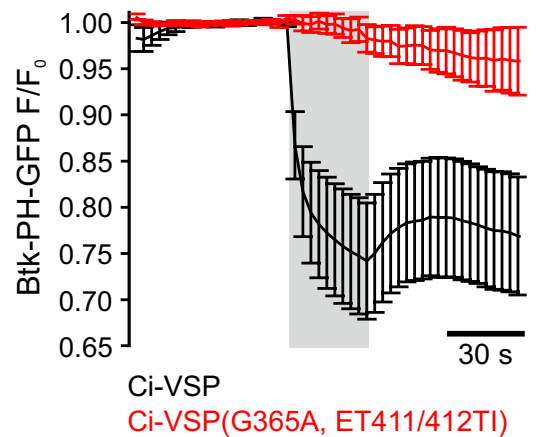

Fig. 2 PTEN $_{\text {Civ }}(\mathrm{A} 126 \mathrm{G}, \mathrm{TI} 167 / 168 \mathrm{ET})$ is a $\mathrm{PI}(3,4,5) \mathrm{P}_{3}$-phosphatase, whereas Ci-VSP(G365,ET411/412TI) lacks detectable PI $(3,4,5) \mathrm{P}_{3^{-}}$ phosphatase activity. a Left panel, representative TIRF image of a CHO cell co-expressing mRFP-PTEN $_{\text {Civ }}(\mathrm{A} 126 \mathrm{G}$, TI167/168ET) and Btk-PH-GFP before (top) and during (bottom) depolarization of the cell membrane through whole-cell patch clamp (scale bar represents $10 \mu \mathrm{m})$. Right panel, summarized TIRF signals in response to

ROI. $F / F_{0}$ traces were corrected for bleaching according to mono-exponential fits to the baseline interval as described previously [37].

\section{Confocal microscopy}

Confocal imaging was performed with an upright LSM 710-Axio Examiner.Z1 microscope equipped with a W-Plan-Apochromat $63 \times / 1.0$ M27 water immersion objective (Carl Zeiss, Jena, Germany) as described before [42]. Red fluorescent protein (RFP) was excited at $561 \mathrm{~nm}$ with a DPSS 561-10 laser (Zeiss) and fluorescence emission was detected at 582-754 $\mathrm{nm}$. Green fluorescent protein (GFP) was excited at $488 \mathrm{~nm}$ with an argon laser and fluorescence emission was detected at $493-556 \mathrm{~nm}$. For confocal imaging, RFP-tagged PTEN and TAPP1-PH-GFP were coexpressed in MDCK cells. Confocal images were processed and montages were generated using ImageJ [40]. Subcellular localization of TAPP1-PH-GFP in MDCK cells co-expressing PTEN wild type, PTEN(C124S) or PTEN(A126G, TI167/168ET) was analyzed by blinded counting of cells with membrane association of TAPP1-PH-GFP.

\section{Quantification of $\mathrm{PI}(3,4) \mathrm{P}_{2}$ levels}

$\mathrm{PI}(3,4) \mathrm{P}_{2}$ was quantified in lysates of PC-3 cells expressing RFP-tagged PTEN wild type, catalytic dead (C124S) or triple mutant (A126G, TI167/168ET) using the $\mathrm{PI}(3,4) \mathrm{P}_{2}$-mass ELISA kit \#K-3800 by Echelon Biosciences (U.S.). $24 \mathrm{~h}$ before transfection, $1 \times 10^{6}$ cells were seeded in 60-mm dishes (in total 5 dishes per construct). step depolarization of the holding potential from -60 to $+80 \mathrm{mV}$ (gray shading) of cells co-expressing wild type RRFP-PTEN $_{\mathrm{CiV}}$

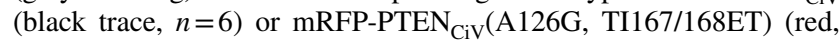
$n=5)$ together with the $\mathrm{PI}(3,4,5) \mathrm{P}_{3}$ sensor Btk-PH-GFP. b Summarized TIRF signals from cells co-expressing wild type mRFP-Ci-VSP (black, $n=9$ ) or mRFP-Ci-VSP(G365A, ET411/412TI) (red, $n=7$ ) together with the $\mathrm{PI}(3,4,5) \mathrm{P}_{3}$ sensor Btk-PH-GFP

Per dish, cells were transfected with $5 \mu$ g DNA pre-mixed with $10 \mu \mathrm{L}$ jetPEI (Polyplus Transfection, France) in $500 \mu \mathrm{L} 150 \mathrm{mM} \mathrm{NaCl} .24 \mathrm{~h}$ after transfection, cells were trypsinized, pooled, and washed once in $5 \mathrm{~mL}$ PBS/10\% (vol/vol) FBS (centrifugation: $2 \mathrm{~min}, 1200 \times g, 4{ }^{\circ} \mathrm{C}$ ). Cells then were resuspended in $1 \mathrm{~mL} \mathrm{PBS} / 10 \%$ (vol/vol) FBS and sorted for RFP-PTEN expression using a BD FACSAria II system (BD Biosciences, San Jose, USA) with an excitation wavelength at $561 \mathrm{~nm}$. After sorting, RFP positive cells were centrifuged for $2 \mathrm{~min}, 1200 \times g$ at $4{ }^{\circ} \mathrm{C}$, resuspended in $3 \mathrm{~mL}$ cell culture media, and seeded in $35-\mathrm{mm}$ dishes. Cells were harvested $24 \mathrm{~h}$ later by trypsinization and washed once in $1 \mathrm{~mL} \mathrm{PBS} / 10 \%$ (vol/vol) FBS $\left(1200 \times g, 2 \mathrm{~min}, 4{ }^{\circ} \mathrm{C}\right)$. Before lipid extraction, vital cells were counted (using trypan blue), and per batch, cell numbers of all samples were adjusted to the same level by dilution in $0.5-1 \mathrm{~mL}$ PBS. Final cell numbers between different batches varied from 1 to $4 \times 10^{4} .1 .5-3 \mathrm{~mL}$ ice cold $0.5 \mathrm{M}$ TCA was added to cell suspensions, and after $5 \mathrm{~min}$ of incubation on ice, cells were centrifuged at $1000 \times g$ for $7 \mathrm{~min}$ at room temperature (RT). Pellets were resuspended in $2 \mathrm{~mL} \mathrm{5 \%}$ (vol/vol) TCA/1 mM EDTA, vortexed for $2 \mathrm{~min}$, and centrifuged at $1000 \times g, 5 \mathrm{~min}$ at RT. This step was repeated once and supernatant was discarded. Neutral lipids were extracted by resuspending the pellet in $1 \mathrm{~mL} \mathrm{MeOH}: \mathrm{CHCl}_{3}(2: 1)$, vortexing for $3 \times 10 \mathrm{~min}$ (with short spin-down between the vortex steps), and final centrifugation at $847 \times g$ for $5 \mathrm{~min}$ at RT. This step was performed twice. Afterwards, acidic lipids were extracted by adding $150 \mu \mathrm{L} \mathrm{MeOH}: \mathrm{CHCl}_{3}: 12 \mathrm{M} \mathrm{HCl}$ (80:40:1), vortexing for $4 \times 15 \mathrm{~min}$ (with short spin-down between the 
vortex steps), and final centrifugation at $847 \times g, 5 \mathrm{~min}$ at RT. Supernatants were transferred into new $2-\mathrm{mL}$ vials. For phase separation, $450 \mu \mathrm{L}$ of $0.1 \mathrm{M} \mathrm{HCl}$ and $250 \mu \mathrm{L}$ $\mathrm{CHCl}_{3}$ were added. Samples were vortexed for $30 \mathrm{~s}$ and centrifuged for $5 \mathrm{~min}$ with $847 \mathrm{xg}$ at RT. The organic (lower) phases were collected into 2 -mL glass vials and dried under vacuum in a desiccator overnight at RT. Dried lipid films were stored at $-20{ }^{\circ} \mathrm{C}$ until usage. Lipids were thawed at RT and then dissolved by adding $0.5-1 \mathrm{~mL}$ pre-warmed $\left(50{ }^{\circ} \mathrm{C}\right)$ PBS-Tween $+3 \%$ protein stabilizer (provided by the Echelon kit), vortexing for $5 \mathrm{~min}$ at RT, and 5 freeze/thaw cycles (freezing in liquid nitrogen, $10 \mathrm{~min}$ at $-20^{\circ} \mathrm{C}$, thawing at $50^{\circ} \mathrm{C}$ for $5 \mathrm{~min}$ in a water bath, and vortexing for $5 \mathrm{~min}$ at RT). Before adding to a 96-well ELISA incubation plate, samples were spun down. $\mathrm{PI}(3,4) \mathrm{P}_{2}$-quantification assay was performed in accordance to the manufacturer's instruction protocol by measuring samples in triplets.

\section{Data analysis/statistics}

Data are presented as mean \pm SEM with $n$ indicating the number of independent recordings (individual cells). Statistical analysis of electrophysiological data was performed with $t$ test or Scheffé/Dunnett test for multiple comparisons. Analysis of $\mathrm{PI}(3,4) \mathrm{P}_{2}$-quantification was done with two-sample $t$ tests without correction for multiple comparisons due to the low numbers of comparisons and to minimize the risk for unwanted type-II errors [43]. Statistical significance was assigned at $P \leq 0.05\left({ }^{*} P \leq 0.05\right.$, $* * P \leq 0.01, * * * P \leq 0.001)$.

\section{Results}

Following established techniques to assess the substrate specificity of voltage-sensitive PI phosphatases in living cells [23, 25, 37], we expressed the enzymes (chimeric PTEN $_{\mathrm{CiV}}$ and Hs-VSP1 $1_{\mathrm{CiV}}$, Ci-VSP) together with GFPtagged PI-binding domains in $\mathrm{CHO}$ cells. Under wholecell voltage clamp to control the activity of the phosphatases, translocation of fluorescent PI sensor domains between plasma membrane and cytosol was monitored using TIRF microscopy. Since this technique allows for selective excitation of fluorophores at the cell membrane, the observed fluorescence intensity reflects the amount of membrane-bound PI sensor molecules, which directly correlates with the respective PI concentration at the membrane surface (Fig. 2a). We utilized the Btk-PH domain for detection of $\mathrm{PI}(3,4,5) \mathrm{P}_{3}$, TAPP1-PH for $\mathrm{PI}(3,4) \mathrm{P}_{2}$, and $\mathrm{PLC}_{1}-\mathrm{PH}$ for $\mathrm{PI}(4,5) \mathrm{P}_{2}$ [44-47]. Additionally, activity of
$\mathrm{PI}(4,5) \mathrm{P}_{2}$-sensitive voltage-gated KCNQ2 $\left(\mathrm{K}_{\mathrm{v}} 7.2\right) \mathrm{K}^{+}$channels was taken as an independent measure for the $\mathrm{PI}(4,5) \mathrm{P}_{2}$ concentration in the plasma membrane [48].

\section{PTEN $_{\text {Civ }}($ A126G, TI167/168ET), but not reciprocal VSP mutants, exhibit activity towards $\mathrm{PI}(3,4,5) \mathrm{P}_{3}$}

Activation of wild type PTEN $\mathrm{CiV}_{\mathrm{C}}$ and Ci-VSP by depolarization of the membrane potential led to dissociation of the $\mathrm{PI}(3,4,5) \mathrm{P}_{3}$-specific probe Btk-PH-GFP from the plasma membrane, as shown by a decrease of the TIRF signal (Fig. 2). These results demonstrated $\mathrm{PI}(3,4,5) \mathrm{P}_{3}$ depletion through PTEN $\mathrm{CiV}_{\text {and }} \mathrm{Ci}$-VSP, as previously reported [25, 37].

In PTEN $\mathrm{CiV}_{\mathrm{CV}}$, simultaneous insertion of the $\mathrm{A} 126 \mathrm{G}$ and the TI167/168ET exchange in P and TI loop, respectively, thereby matching the sequence of VSPs with regard to amino acid residues lining the active site, preserved activity towards $\mathrm{PI}(3,4,5) \mathrm{P}_{3}$ (Fig. 2a). In contrast, reciprocal mutations in Ci-VSP abolished phosphatase $\mathrm{PI}(3,4,5) \mathrm{P}_{3}$ activity (Fig. 2b).

These findings demonstrated that PTEN(A126G, TI167/168ET) exhibited activity toward PI $(3,4,5) \mathrm{P}_{3}$. However, these experiments did not give any insight into sitespecific activity of the PTEN $\mathrm{CiV}_{\mathrm{C}}$ mutants. Thus, we subsequently used reporters specific for $\mathrm{PI}(3,4) \mathrm{P}_{2}$ or $\mathrm{PI}(4,5) \mathrm{P}_{2}$ to clarify this question.

\section{PTEN $_{\text {Civ }}$ (A126G, TI167/168ET), PTEN Civ $_{\text {(TI167/168ET) }}$

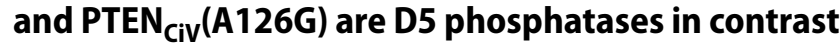 to wild type PTEN $_{\text {Civ }}$}

For analysis of site-specific activity of the PTEN $\mathrm{CiV}_{\mathrm{V}}$ and VSPs mutants, we used TAPP1-PH-GFP to monitor $\mathrm{PI}(3,4) \mathrm{P}_{2}$ levels at the cell membrane during voltagedependent activation of the phosphatases (Fig. 3).

Upon activation of wild type PTEN $\mathrm{CiV}_{\mathrm{Ci}}$ by membrane potential depolarization, the fluorescence signal of TAPP1PH-GFP measured with TIRF microscopy decreased due to dissociation of the sensor from the cell membrane (Fig. 3b). These results showed $\mathrm{PI}(3,4) \mathrm{P}_{2}$ depletion through the chimeric enzyme, in line with previous studies on native PTEN [1-4] and PTEN ${ }_{\mathrm{CiV}}$ [37].

In contrast to the wild type, in cells co-expressing PTEN $_{\text {CiV }}$ carrying the three mutations A126G in the P loop and TI167/168ET in the TI loop depolarization of the membrane potential led to an increase in TAPP1-PH-GFP fluorescence at the membrane (Fig. 3b). This observation reflected $\mathrm{PI}(3,4) \mathrm{P}_{2}$ production upon voltage-dependent activation of the enzyme. Taking into account that this triple mutant depleted $\mathrm{PI}(3,4,5) \mathrm{P}_{3}$ (Fig. 2a), these findings characterized 
A

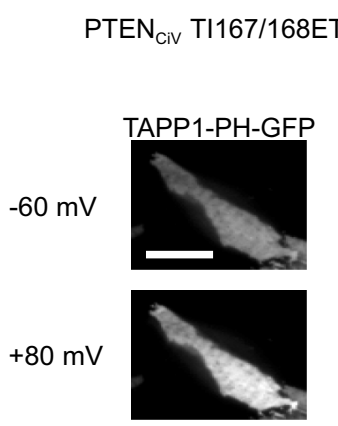

D

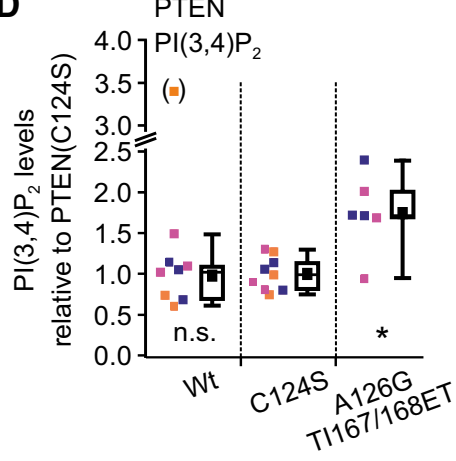

cell batch: $\approx 1 \square \# 2 \approx \# 3$
B

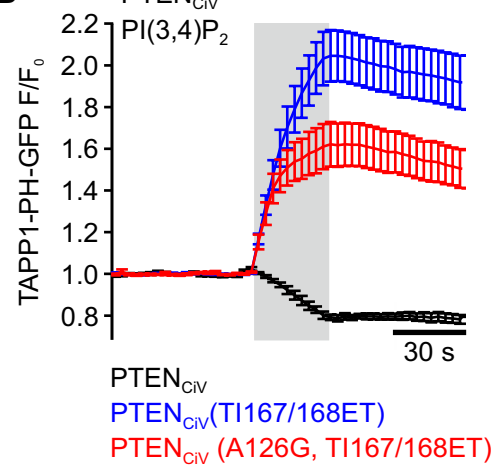

E

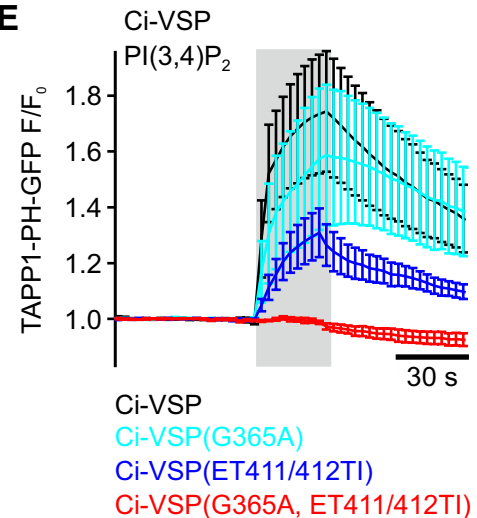

PTEN $_{\text {Civ }}($ TI167/168ET)

TEN $_{\text {Civ }}($ A126G, TI167/168ET)

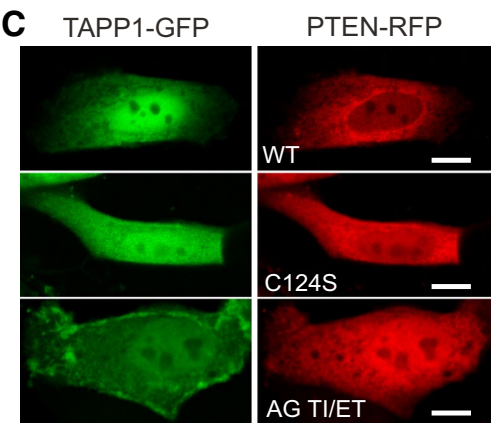

$\mathbf{F}$

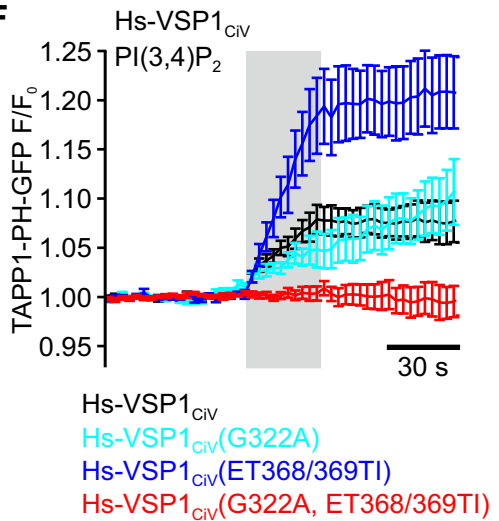

Fig. $3 \mathrm{PI}(3,4) \mathrm{P}_{2}$ production through native PTEN, PTEN $\mathrm{CiV}_{\text {and }}$ VSP mutants demonstrates $\mathrm{PI}(3,4,5) \mathrm{P}_{3}$-D5-phosphatase activity. a Representative TIRF image of a CHO cell co-expressing mRFPPTEN $_{\mathrm{CiV}}$ (TI167/168ET) and TAPP1-PH-GFP before (top) and during (bottom) depolarization of the cell membrane through whole-cell patch clamp (scale bar represents $10 \mu \mathrm{m}$ ). b, e, f Summarized TIRF signals in response to step depolarization from -60 to $+80 \mathrm{mV}$ (gray shading) of cells co-expressing the $\mathrm{PI}(3,4) \mathrm{P}_{2}$ sensor TAPP1-PHGFP with $\mathbf{b}$ wild type mRFP-PTEN $_{\mathrm{CiV}}$ (black trace, $n=6$ ), mRFPPTEN $_{\mathrm{CiV}}\left(\mathrm{TI} 167 / 168 \mathrm{ET}\right.$ ) (blue, $n=7$ ) or $\operatorname{mRFP} \mathrm{PTEN}_{\mathrm{CiV}}(\mathrm{A} 126 \mathrm{G}$, TI167/168ET) (red, $n=8$ ), e wild type mRFP-Ci-VSP (black, $n=7$ ), mRFP-Ci-VSP(G365A) (cyan, $n=7$ ), mRFP-Ci-VSP(ET411/412TI) (blue, $n=8$ ), or mRFP-Ci-VSP(G365A, ET411/412TI) (red, $n=10$ ), and $\mathbf{f}$ wild type $\mathrm{mRFP}^{-H s-V S P} 1_{\mathrm{CiV}}$ (black, $n=6$ ), mRFP-Hs$\mathrm{VSP}_{\mathrm{CiV}}(\mathrm{G} 322 \mathrm{~A})$ (cyan, $\left.n=6\right), \quad \mathrm{mRFP}_{-\mathrm{Hs}}-\mathrm{VSP} 1_{\mathrm{CiV}}(\mathrm{ET} 368 / 369 \mathrm{TI})$ (blue, $n=7$ ), or mRFP-Ci-VSP(G322A, ET368/369TI) (red, $n=7)$. c The panel shows representative confocal images of MDCK cells coexpressing TAPP1-PH-GFP together with wild type PTEN (top),

PTEN $_{\text {CiV }}($ A126G, TI167/168ET) as a D5 phosphatase of $\mathrm{PI}(3,4,5) \mathrm{P}_{3}$.

We next analyzed whether the triple mutation also changed the substrate specificity of soluble (native) PTEN not coupled to a voltage-sensor domain. To this end, we co-expressed PTEN (wild type and mutant) together with TAPP1-PH-GFP in MDCK cells and analyzed membrane association of the $\mathrm{PI}(3,4) \mathrm{P}_{2}$ reporter with confocal microscopy (Fig. 3c; Fig. S2). TAPP1-PH-GFP was localized in the cytoplasm without any evident membrane association
PTEN(C124S) (middle), and PTEN(A126G, TI167/168ET) (bottom) (PTEN constructs were N-terminally tagged with RFP, all scale bars represent $10 \mu \mathrm{m}$; see Supplementary Fig. 2 for all analyzed cells). d PI $(3,4) \mathrm{P}_{2}$-levels were quantified by ELISA in independent triplets (three independent batches of PC-3 cells) expressing RFPtagged soluble PTEN(wild type), PTEN(C124S), or PTEN(A126G, TI167/168ET). Note that for batch\#1/wild type one outlier value was excluded from statistical analysis (marked with parentheses). $\mathrm{PI}(3,4) \mathrm{P}_{2}$ concentrations obtained per batch and PTEN construct were normalized to the arithmetic mean calculated for the respective C124S-triplet. Individual (normalized) experiments are displayed together with summarized data (in boxplot representation: blackfilled squares denote arithmetic means over all normalized values for each experimental condition). Statistical analysis was performed over all normalized values by two-sample $t$ tests in comparison to PTEN(C124S): n.s. no statistical difference (PTEN(Wt)); ${ }^{*} P \leq 0.05$ (PTEN(A126G. TI167/168ET)). Number of independent experiments: $n=3$ for wild type and C124S, and $n=2$ for the PTEN triple mutant)

in all cells co-expressing wild type PTEN (42 cells analyzed in total; Fig. 3c and Fig. S2A). For catalytically inactive PTEN(C124S), membrane association of the PI $(3,4) \mathrm{P}_{2}$ reporter was observable in only 1 cell ( 36 cells analyzed; Fig. 3c and Fig. S2B). Markedly, we found clear membrane association of TAPP1-PH-GFP in approximately $37 \%$ of all cells co-expressing PTEN(A126G, TI167/168ET) (Fig. S2C). These findings demonstrated that expression of the PTEN triple mutant caused a pronounced increase in $\mathrm{PI}(3,4) \mathrm{P}_{2}$ levels in the membrane of MDCK cells. Indeed, 
as quantified with $\mathrm{PI}(3,4) \mathrm{P}_{2}$-mass ELISA (c.f. ref. [35]), we observed a significant increase in $\mathrm{PI}(3,4) \mathrm{P}_{2}$ levels in PC-3 cells expressing PTEN(A126G, TI167/168ET) in comparison to cells expressing PTEN wild type or the catalytically dead mutant C124S ( $P \leq 0.05$; Fig. 3d). Thus, based on these results obtained with two independent cellular assays, we conclude that, just as for PTEN $\mathrm{CiV}_{\text {, }}$ the three mutations in P and TI loop also conferred D5 site activity toward $\mathrm{PI}(3,4,5) \mathrm{P}_{3}$ to native PTEN.

As such, D5 site-specific activity has also been described recently for the P loop mutant A126G in soluble PTEN and chimeric PTEN ${ }_{\mathrm{CiV}}$ [35], a single amino acid exchange in the active site apparently was sufficient to confer D5 activity to PTEN. We thus decided to further analyze the significance of the TI/ET mutation. Remarkably, the TI167/168ET mutations alone also induced D5 site activity toward $\mathrm{PI}(3,4,5) \mathrm{P}_{3}$ in $\mathrm{PTEN}_{\mathrm{CiV}}$, as evident by an increase of TAPP1-PH-GFP fluorescence at the membrane, representing $\mathrm{PI}(3,4) \mathrm{P}_{2}$ production during voltage-dependent activation (Fig. 3a, b). Thus, the A126G mutation in the P loop and the TI/ET exchange in the TI loop independently conferred "VSP-like" D5 site activity toward $\mathrm{PI}(3,4,5) \mathrm{P}_{3}$ to the otherwise D3 site-specific phosphatase PTEN $_{\mathrm{CiV}}$.

Given the high degree of sequence similarity between VSPs and PTEN (Fig. S1), we next studied the effect of PTEN-like mutations in the $\mathrm{P}$ or the TI/gating loop of CiVSP and $\mathrm{Hs}-\mathrm{VSP} 1_{\mathrm{CiV}}$. For both, the G/A exchange or the ET/ TI mutations, TAPP1-PH-GFP translocated to the membrane during depolarization, similarly to translocation during activation of wild type VSPs (Fig. 3e, f). Since this fluorescence dynamics demonstrated production of $\mathrm{PI}(3,4) \mathrm{P}_{2}$, we conclude that the pre-dominant D5 site activity of Ci-VSP and Hs-VSP $1_{\mathrm{CiV}}$ toward PI $(3,4,5) \mathrm{P}_{3}$ was not altered by introduction of these mutations individually. Of note-apart from the ET368/369TI mutations in $\mathrm{Hs}-\mathrm{VSP} 1_{\mathrm{CiV}}$ - the mutations in the $\mathrm{P}$ or TI/gating loop reduced phosphatase activity of $\mathrm{Ci}-\mathrm{VSP}$ and $\mathrm{Hs}-\mathrm{VSP} 1_{\mathrm{CiV}}$, as mirrored in the less pronounced membrane translocation of the $\mathrm{PI}(3,4) \mathrm{P}_{2}$ probe TAPP1-PHGFP during depolarization compared to the respective wild types enzymes (Fig. 3e, f).

When $\mathrm{P}$ and TI/gating loop mutations were both introduced into Ci-VSP and $\mathrm{Hs}-\mathrm{VSP} 1_{\mathrm{CiV}}$, the fluorescence signal of TAPP1-PH-GFP remained constant upon activation of the enzymes (Fig. 3e, f) indicating no changes in the membrane $\mathrm{PI}(3,4) \mathrm{P}_{2}$ concentration. In line with the absent activity of the triple mutant of Ci-VSP toward $\mathrm{PI}(3,4,5) \mathrm{P}_{3}$ (c.f. Fig. $2 b$ ), these results also indicated lack of phosphatase activity of the VSP mutants carrying both, the P mutation and the TI/ gating loop exchange.

In summary, individual and combined $\mathrm{P}$ and $\mathrm{TI} /$ gating loop mutations conferred VSP-like D5 site activity toward $\mathrm{PI}(3,4,5) \mathrm{P}_{3}$ to $\mathrm{PTEN}_{\mathrm{CiV}}$. In contrast, reciprocal mutations reduced or even abolished phosphatase activity of native VSPs.

\section{PTEN $_{\text {civ }}(\mathrm{A} 126 \mathrm{G}, \mathrm{TI167/168ET})$ fully reproduces substrate specificity and site-specific activity of native VSPs}

Using PI $(4,5) \mathrm{P}_{2}$-specific $\mathrm{PLC}_{1}$-PH-GFP domain as biosensor, we then analyzed whether PTEN $\mathrm{CiV}_{\mathrm{C}}$ and VSP mutants exhibited $\mathrm{D} 3$ site activity toward $\mathrm{PI}(3,4,5) \mathrm{P}_{3}$ or $\mathrm{D} 5$ site activity toward $\mathrm{PI}(4,5) \mathrm{P}_{2}$. To this end, the TIRF-based assay using the fluorescently labeled $\mathrm{PI}(4,5) \mathrm{P}_{2}$ binding domain was complemented with whole-cell patch clamp recordings of currents through KCNQ2 channels as an alternative $\mathrm{PI}(4,5) \mathrm{P}_{2}$ sensor [48]. Control experiments with Ci-VSP showed robust inhibition of KCNQ2 currents (Fig. 4d, and Fig. S3A), demonstrating $\mathrm{PI}(4,5) \mathrm{P}_{2}$ breakdown upon activation of Ci-VSP and, thus, applicability of our approach [49].

In cells co-expressing $\mathrm{PTEN}_{\mathrm{CiV}}$, depolarization led to a slight increase in $\mathrm{PLC}_{1}$-PH-GFP fluorescence in the TIRF recordings (Fig. 4a), indicating $\mathrm{PI}(4,5) \mathrm{P}_{2}$ production at the membrane. In combination with $\mathrm{PTEN}_{\mathrm{CiV}^{-}}$-dependent $\mathrm{PI}(3,4,5) \mathrm{P}_{3}$ depletion (Fig. 2a), these findings demonstrated that PTEN $\mathrm{CiV}_{\mathrm{C}}$ dephosphorylated $\mathrm{PI}(3,4,5) \mathrm{P}_{3}$ at the D3 position.

In contrast, membrane binding of $\mathrm{PLC}_{1}$-PH-GFP was not affected by activation of PTEN $\mathrm{CiV}_{\mathrm{Ci}}$ carrying the TI loop mutations TI167/168ET indicating lack of phosphatase activity toward PI(4,5) $\mathrm{P}_{2}$ (Fig. 4a). In support of these findings, KCNQ2-mediated currents were also not reduced by

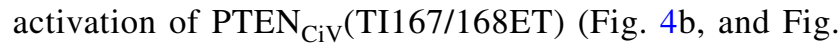
S3B). Since activation of this mutant caused accumulation of $\mathrm{PI}(3,4) \mathrm{P}_{2}$ at the membrane (c.f. Fig. 3b) without altering $\mathrm{PI}(4,5) \mathrm{P}_{2}$ concentrations (Fig. $4 \mathrm{a}, \mathrm{b}$ ), these findings demonstrated D5 site activity toward $\mathrm{PI}(3,4,5) \mathrm{P}_{3}$, but not toward $\mathrm{PI}(4,5) \mathrm{P}_{2}$ for $\mathrm{PTEN}_{\mathrm{CiV}}(\mathrm{TI} 167 / 168 \mathrm{ET})$.

Similarly, we showed recently that the P loop mutation A126G changed the D3 site activity of PTEN ${ }_{\mathrm{CiV}}$ to D5 site activity solely toward $\mathrm{PI}(3,4,5) \mathrm{P}_{3}$ [35]. Here, we confirmed lack of $\mathrm{PI}(4,5) \mathrm{P}_{2}$ activity of this mutant with electrophysiological recordings, as $\operatorname{PTEN}_{\mathrm{CiV}}(\mathrm{A} 126 \mathrm{G})$ failed to inhibit KCNQ2 currents (Fig. 4b, and Fig. S3B). Thus, we conclude that $\mathrm{PI}(4,5) \mathrm{P}_{2}$ did not serve as substrate of PTEN $_{\mathrm{CiV}}$ (A126G).

Taken together, P and TI loop mutations independently conferred D5 site activity toward $\mathrm{PI}(3,4,5) \mathrm{P}_{3}$, but not toward $\mathrm{PI}(4,5) \mathrm{P}_{2}$ to $\mathrm{PTEN}_{\mathrm{Civ}}$. Thus, these $\mathrm{PTEN}_{\mathrm{CiV}}$ mutations did not fully recapitulate the phenotype of native VSPs.

When the mutations were introduced simultaneously into PTEN $\mathrm{CiV}_{\mathrm{C}}$ (A126G and TI167/168ET into P and TI loop, respectively), voltage-dependent stimulation caused a decrease in PLC $_{1}$-PH-GFP fluorescence at the membrane (Fig. 4a) and substantially inhibited KCNQ2 
Fig. 4 Depletion of $\mathrm{PI}(4,5) \mathrm{P}_{2}$ by mutants of PTEN $\mathrm{CiV}_{\mathrm{V}}$ and VSPs demonstrates $\mathrm{PI}(4,5) \mathrm{P}_{2}$-phosphatase activity. Summarized TIRF signals in response to step depolarization from -60 to $+80 \mathrm{mV}$ (gray shading) of cells co-expressing the $\mathrm{PI}(4,5) \mathrm{P}_{2}$ sensor $\mathrm{PLC \delta}_{1}$-PH-GFP and the indicated $\mathrm{mRFP}$-tagged mutants of a PTEN $\mathrm{CiV}_{\mathrm{V}}$, c Ci-VSP, or e Hs-VSP1 $1_{\mathrm{CiV}}$. Summarized KCNQ2 currents in response to voltage-dependent activation of the indicated mutants of $\mathbf{b}$ PTEN $_{\mathrm{CiV}}, \mathbf{d} \mathrm{Ci}-\mathrm{VSP}$, or $\mathbf{f}$ Hs-VSP1 $1_{\mathrm{CiV}}$. Holding potential was $-60 \mathrm{mV}$ and phosphatases were activated at $+80 \mathrm{mV}$ for $30 \mathrm{~s}$. KCNQ2 currents were recorded at $0 \mathrm{mV}$. See Fig. S3 for voltage protocol and representative current recordings. b $* * P \leq 0.01$ indicates significant difference to PTEN $\mathrm{CiV}_{\mathrm{V}}$ wt. d $* * P \leq 0.01$ and $* * * P \leq 0.001$ indicate significant difference to catalytically dead mutant $\mathrm{Ci}$ $\operatorname{VSP}(\mathrm{C} 363 \mathrm{~S}) . \mathbf{f} * * P \leq 0.01$ and $* * * P \leq 0.001$ indicate significant difference to $\mathrm{Hs}-\mathrm{VSP} 1_{\mathrm{CiV}}$ wt. a Wild type mRFP-PTEN ${ }_{\mathrm{CiV}}$ (black trace, $n=5$ ), mRFPPTEN $_{\mathrm{CiV}}(\mathrm{TI} 167 / 168 \mathrm{ET})$ (blue, $n=7$ ) or mRFPPTEN $_{\mathrm{CiV}}(\mathrm{A} 126 \mathrm{G}$,

TI167/168ET) (red, $n=8)$, c wild type mRFP-Ci-VSP (black, $n=9$ ), mRFP-CiVSP(G365A) (cyan, $n=5$ ), mRFP-Ci-VSP(ET411/412TI)

(blue, $n=11$ ), or mRFP-CiVSP(G365A, ET411/412TI) (red, $n=8$ ), and e wild type mRFP-Hs-VSP1 $1_{\mathrm{CiV}}$ (black, $n=6$ ), mRFPHs-VSP $1_{\mathrm{CiV}}(\mathrm{G} 322 \mathrm{~A})$ (cyan, $n=8$ ), mRFP- Hs$\mathrm{VSP}_{\mathrm{CiV}}(\mathrm{ET} 368 / 369 \mathrm{TI})$ (blue, $n=7$ ), or mRFP-CiVSP(G322A, ET368/369TI) (red, $n=5$ )

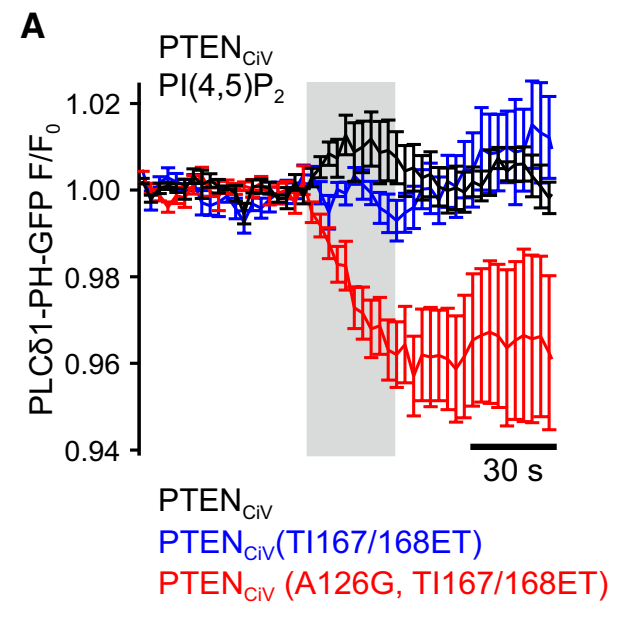

B PTEN $_{\text {Civ }}$
PI $(4,5) \mathrm{P}_{2}$

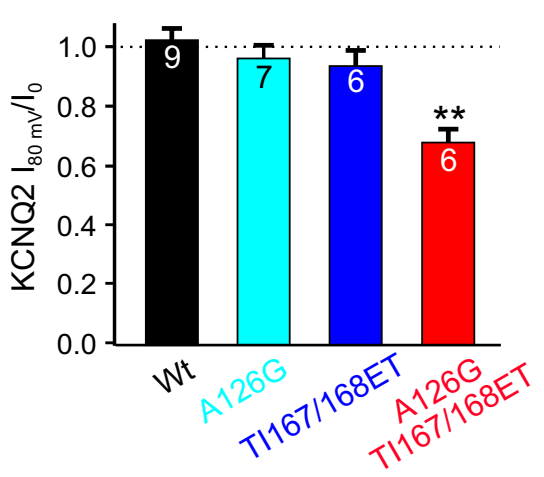

D Ci-VSP

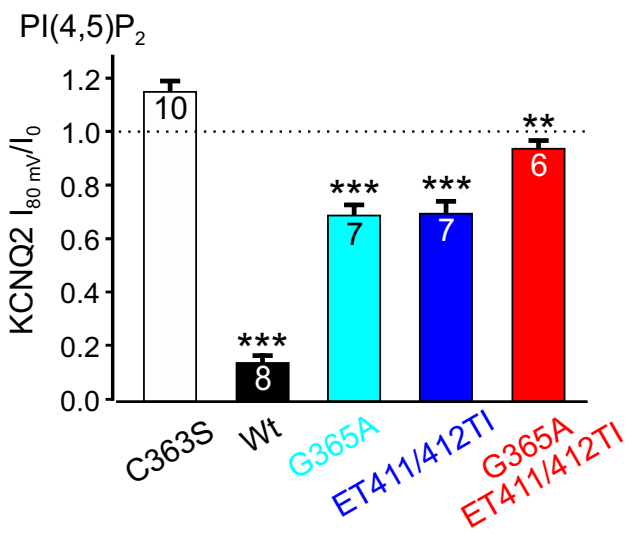

E

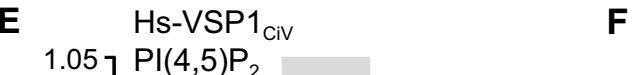

Hs-VSP $1_{\text {CiV }}$ $\mathrm{PI}(4,5) \mathrm{P}_{2}$

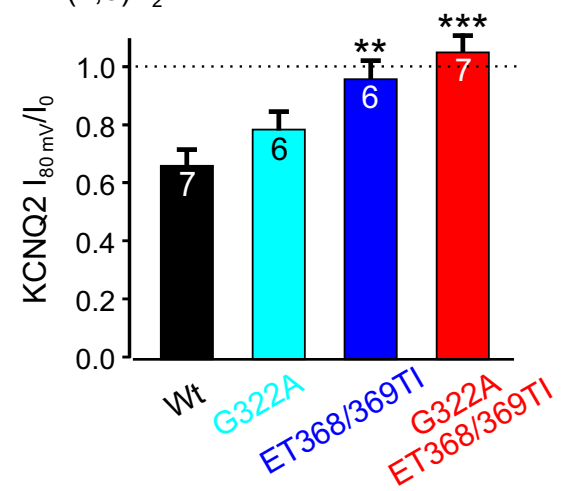

currents (Fig. 4b and Fig. S3B). Both observations demonstrated $\mathrm{PI}(4,5) \mathrm{P}_{2}$ depletion by $\mathrm{PTEN}_{\mathrm{CiV}}(\mathrm{A} 126 \mathrm{G}$, TI167/168ET). Thus, these three amino acid exchanges in the active site as well as the TI loop, converted otherwise
D3 specific PTEN $\mathrm{CiV}_{\text {in }}$ into a D5 phosphatase that completely reproduced the pre-dominant substrate specificity of native VSPs. 


\section{Mutations in $\mathrm{P}$ and gating loop reduce activity of native VSPs}

In line with the pre-dominant D5 site phosphatase activity of native Ci-VSP and $\mathrm{Hs}-\mathrm{VSP} 1_{\mathrm{CiV}}$ [23-28, 30], depolarization of the membrane potential decreased $\mathrm{PLC} \delta_{1}$-PH-GFP membrane binding (Fig. 4c, e) and reduced KNCQ2 currents, when the wild type enzymes were co-expressed (Fig. 4d, f). When the G/A mutation was introduced into the P loop of these VSPs (G365A for Ci-VSP and G322A for Hs-VSP$1_{\mathrm{CiV}}$, Fig. 1b), no qualitative change in their PI(4,5) $\mathrm{P}_{2}$ D5 phosphatase activity was observed in the TIRF assay with $\mathrm{PLC}_{1}$-PH-GFP (Fig. 4c, e) or in the patch clamp recordings using KCNQ2 currents as $\mathrm{PI}(4,5) \mathrm{P}_{2}$ sensors (Fig. 4d, f; Fig. S3A, C). Quantitatively, decrease in PLC81-PH-GFP fluorescence was reduced and inhibition of KCNQ2 currents was attenuated for $\mathrm{Ci}-\mathrm{VSP}(\mathrm{G} 365 \mathrm{~A})$ in comparison to the wild type enzyme (Fig. 4c, d). Upon activation of Hs$\mathrm{VSP}_{\mathrm{CiV}}(\mathrm{G} 322 \mathrm{~A})$, only minor changes in PLC81-PH-GFP fluorescence were detected (Fig. 4e). However, the mutant still depleted $\mathrm{PI}(4,5) \mathrm{P}_{2}$ as demonstrated by inhibition of KCNQ2-mediated currents (Fig. 4f), although channel inhibition was reduced compared to wild type Hs-VSP1 $1_{\mathrm{CiV}}$.

For the gating loop mutations ET411/412TI in Ci-VSP, membrane dissociation of $\mathrm{PLC}_{1}$-PH-GFP and inhibition of KCNQ2 currents were still observable (Fig. 4c, d). These results demonstrated $\mathrm{PI}(4,5) \mathrm{P}_{2}$ consumption by this mutant, although phosphatase activity was reduced compared to the wild type enzyme. In contrast, we did not detect changes in $\mathrm{PI}(4,5) \mathrm{P}_{2}$ levels upon activation of HsVSP1 $_{\mathrm{CiV}}(\mathrm{ET} 368 / 369 T I)$ (Fig. 4e, f and Fig. S3C).

As for the gating loop mutant, for the triple Hs$\mathrm{VSP}_{\mathrm{CiV}}(\mathrm{G} 322 \mathrm{~A}, \mathrm{ET} 368 / 369 \mathrm{TI})$ mutant, voltage-dependent reduction in $\mathrm{PI}(4,5) \mathrm{P}_{2}$ concentration was not detectable (Fig. 4e, f). In contrast, Ci-VSP(G365A, ET411/412TI) exhibited residual activity toward $\mathrm{PI}(4,5) \mathrm{P}_{2}$ as seen in minute translocation of PLC $\delta_{1}$-PH-GFP (Fig. 4c) and in a slight, albeit significant inhibition of KCNQ2 currents (Fig. 4d, Fig. S3A).

Taken together, insertion of PTEN-like mutations into the $\mathrm{P}$ and gating loop of native VSPs reduces or even abolished $\mathrm{PI}(4,5) \mathrm{P}_{2}$ phosphatase activity of Ci-VSP and $\mathrm{Hs}-\mathrm{VSP} 1_{\mathrm{CiV}}$.

\section{Discussion}

Despite high similarity in sequence and structure, PTEN and VSPs differ in their reaction specificity. The reason for this discrepancy is not known. In this study, we shed light on this question by systematically exchanging amino acids in the active site motif (P loop) and the TI or "gating loop" that both form parts of the substrate binding pocket. Our results (summarized in Table 1) provide insights into the
Table 1 Summary of observed enzymatic activities of PTEN ${ }_{\mathrm{CiV}}$ and VSPs mutants

\begin{tabular}{|c|c|c|c|c|}
\hline \multirow{2}{*}{$\begin{array}{l}\text { Substrate } \\
\text { Position }\end{array}$} & \multicolumn{2}{|c|}{$\mathrm{PI}(3,4,5) \mathrm{P}_{3}$} & \multirow{2}{*}{$\begin{array}{l}\mathrm{PI}(3,4) \mathrm{P}_{2} \\
\text { D3 }\end{array}$} & \multirow{2}{*}{$\begin{array}{l}\mathrm{PI}(4,5) \mathrm{P}_{2} \\
\text { D5 }\end{array}$} \\
\hline & D3 & D5 & & \\
\hline $\mathrm{PTEN}_{\mathrm{CiV}}$ & + & - & + & - \\
\hline $\mathrm{PTEN}_{\mathrm{CiV}}(\mathrm{A} 126 \mathrm{G})$ & - & + & - & - \\
\hline PTEN $_{\mathrm{CiV}}(\mathrm{TI} 167 / 168 \mathrm{ET})$ & - & + & - & - \\
\hline $\begin{array}{l}\text { PTEN }_{\mathrm{CiV}}(\mathrm{A} 126 \mathrm{G}, \mathrm{TI} 167 / 16 \\
\text { 8ET) }\end{array}$ & - & + & - & + \\
\hline VSP & - & + & - & + \\
\hline VSP(G/A) & - & + & - & + \\
\hline VSP(ET/TI) & - & + & - & + \\
\hline VSP(G/A, ET/TI) & - & - & - & - \\
\hline
\end{tabular}

'+' indicates activity, ' - ' indicates lack thereof. Since the activity of $\mathrm{Hs}-\mathrm{VSP} 1_{\mathrm{CiV}}$ is qualitatively identical to that of $\mathrm{Ci}-\mathrm{VSP}$, both VSPs have been summarized. 'G/A' refers to 'G365A' for Ci-VSP and 'G322A' for Hs-VSP1 $1_{\mathrm{CiV}}$, 'ET/TI' to 'ET411/412TI' for Ci-VSP and 'ET368/369TI' for Hs-VSP1. Information on PTEN $\mathrm{CiV}_{(\mathrm{A} 126 \mathrm{G}) \text { is }}$ taken from Costa et al. [35]

structural origin of the substrate specificity of PTEN: (i) The exchange of the TI loop signature motif with the ET pair of VSPs changed phosphatase activity of PTEN $\mathrm{CiV}_{\mathrm{V}}$ from D3 - to a VSP-like D5 site specificity toward $\mathrm{PI}(3,4,5) \mathrm{P}_{3}$. (ii) In $\mathrm{PTEN}_{\mathrm{CiV}}$, combining TI/ET loop mutations with the alanine-to-glycine exchange in the $\mathrm{P}$ loop, removing major sequence differences to native VSPs, induced D5 site activity toward both, $\mathrm{PI}(3,4,5) \mathrm{P}_{3}$ and $\mathrm{PI}(4,5) \mathrm{P}_{2}$. Thus, the $\mathrm{PTEN}_{\mathrm{CiV}}$ triple mutant fully reproduced the phosphatase phenotype of Ci-VSP. Importantly, our results unequivocally demonstrated that the same amino acid residues also determine substrate specificity of native (soluble) PTEN. (iii) In contrast, reciprocal mutations in Ci-VSP and $\mathrm{Hs}-\mathrm{VSP} 1_{\mathrm{CiV}}$ did not alter substrate specificity, but reduced or even abolished their phosphatase activity.

\section{PTEN $_{\text {Civ }}$ is an established tool to study substrate specificity of native PTEN}

Recently, we engineered chimeric voltage-sensitive PTEN $\mathrm{CiV}_{\mathrm{C}}$ by fusing the voltage sensor of Ci-VSP to the catalytically active domain of PTEN (originally named "CiVSPTEN16") [37]. We could demonstrate that this chimeric enzyme is rapidly switched on by depolarizing the membrane potential precisely reproducing the well-known D3 site phosphatase activity of native PTEN [35, 37, 42]. Furthermore, we here directly show that mutations in gating and TI loops change substrate specificity of native PTEN and PTEN ${ }_{\mathrm{CiV}}$ precisely the same way. Thus, $\mathrm{PTEN}_{\mathrm{CiV}}$ is a suitable tool to study catalytic mechanisms of the tumor suppressor PTEN. Importantly, substrate specificity of the enzyme can easily be monitored in living cells with the combination of TIRF 
microscopy and patch clamp technique that is well-established for studies of VSPs [23, 25, 37]. This approach entails two remarkable advantages: (i) Direct and rapid control of phosphatase activity by membrane voltages enables the exact differentiation of cellular responses before, during and after the catalytic reaction. Consequently, changes in concentrations of discrete PI species at the plasma membrane can be determined with high spatiotemporal precision to characterize substrate specificity of the phosphatase. (ii) Chimeric enzymes allow for characterization of phosphatase activity in native lipid environments. Artificial membrane systems or vesicles, which are normally used to study phosphatase activity of PTEN and its homologs in vitro, hardly mimic the complex lipid composition of cellular membranes. In particular, it is well-established that with phosphatidylserine and $\mathrm{PI}(4,5) \mathrm{P}_{2}$, two lipids crucially regulate phosphatase activity of PTEN, either by mediating membrane binding of the enzyme or by allosterically activating the catalytic reaction [3,50-55]. Thus, results obtained in vitro and in cellular assays frequently diverge. As a case in point, Hs-VSP1 was originally described as PI phosphatase with PTEN-like D3 site substrate specificity in vitro [21]. Taking into account that Hs-VSP1 shares higher sequence homology in P and gating loop to D5 site phosphatases (such as Ci-VSP) than to PTEN (Fig. 1b and Fig. S1), the claim of D3 site specificity was somewhat surprising. Finally, studies on Hs-VSP1 utilizing the $\mathrm{Hs}-\mathrm{VSP} 1_{\mathrm{CiV}}$ chimera in living cells that allow for measurements under more physiological conditions demonstrated its actual VSP-like D5 site activity [23].

Therefore, we conclude that artificial membrane systems are well suitable to detect phosphatase activity of PTEN and its homologs in general, but cellular membranes are better suited to study the substrate specificity of these phosphatases in their native lipid environment.

\section{Determinants of substrate specificity of PTEN}

In PTEN and VSPs, at least three loops (P, TI/gating and WPD loop) form the substrate binding pocket (Fig. 1c). With less than $1 \AA$ deviation in the $\mathrm{C} \alpha$ trace of the protein backbone, the P loop shows only minor structural differences among the phosphatases [27, 34] and differs only in one alanine (PTEN) to glycine (VSPs) exchange (Fig. 1b). The A126G exchange shifts substrate specificity of PTEN CiV $_{\text {. }}$ from pure D3 to D5 site activity toward $\mathrm{PI}(3,4,5) \mathrm{P}_{3}$ and abolishes activity toward $\mathrm{PI}(3,4) \mathrm{P}_{2}$ [35]. Here, we confirmed that $\operatorname{PTEN}_{\mathrm{CiV}}(\mathrm{A} 126 \mathrm{G})$ is not active toward $\mathrm{PI}(4,5) \mathrm{P}_{2}$ using $\mathrm{KCNQ} 2$ channels as read-out. These findings indicate that the alanine in the active site motif might be crucial for establishing D3 site activity in PTEN, but however additional structural properties of the substrate binding pocket may be required to establish full D5 phosphatase activity of native VSPs in PTEN.
Indeed, the canonic TI pair has already been suggested to play a role in substrate binding of PTEN. Lee et al. considered $\mathrm{T} 167$ as important for positioning a $\mathrm{PI}(3,4,5) \mathrm{P}_{3}$ molecule into the active site, since they observed close vicinity between this residue and the D4/D5 sites of $\operatorname{Ins}(1,3,4,5) \mathrm{P}_{4}$ in an X-ray-based structural model [32]. Hypothetically, these interactions could stabilize the binding between the D3 site of $\mathrm{PI}(3,4,5) \mathrm{P}_{3}$ and the catalytic residue $\mathrm{C} 124$. Thus, mutating T167 might alter $\mathrm{PI}(3,4,5) \mathrm{P}_{3}$ binding in such a way that the D5 site is no longer stabilized by the TI pair, so that it can bind to the catalytic center. Furthermore, homologous positions of the TI pair in other PTPs, including VSPs, were shown to interfere with catalysis [31]. Mutating TI167/168 into their VSP counterpart ET readily converted PTEN ${ }_{\mathrm{CiV}}$ into a $\mathrm{PI}(3,4,5) \mathrm{P}_{3}$-D5 site-specific phosphatase with no activity toward $\mathrm{PI}(3,4) \mathrm{P}_{2}$ and $\mathrm{PI}(4,5) \mathrm{P}_{2}$, which reproduces the phenotype of PTEN $\mathrm{CiV}_{\mathrm{C}}$ (A126G). Thus, the P and TI loop mutations independently determine site specificity of PTEN $_{\text {CiV }}$ toward PI $(3,4,5) \mathrm{P}_{3}$, but did not allow for VSP-like $\mathrm{PI}(4,5) \mathrm{P}_{2}$-D5 site activity. Only the combination of $\mathrm{P}$ and TI loop mutations produced the full phenotype of VSPs enabling dephosphorylation activity toward the D5 site of both substrates, $\mathrm{PI}(3,4,5) \mathrm{P}_{3}$ and $\mathrm{PI}(4,5) \mathrm{P}_{2}$. Noteworthy, the same combination of mutations also changed the substrate specificity of native (soluble) PTEN demonstrating that the same residues determine substrate specificity of the tumor suppressor in living cells. Based on our results, we conclude that A126 and TI167/168 are determinants for the substrate specificity in PTEN, whereby simultaneous mutations on both sites additively affect enzymatic activity.

\section{The role of the P loop glycine for the phosphatase activity of VSPs}

Sequence comparison reveals that all known VSPs possess a glycine in their $\mathrm{HCX}_{5} \mathrm{R}$ motif, whereas PTEN shows an alanine at this position (Fig. 1b). Thus, it was tempting to speculate that the glycine determines VSP-like D5 site activity toward $\mathrm{PI}(3,4,5) \mathrm{P}_{3}$ and $\mathrm{PI}(4,5) \mathrm{P}_{2}[20,23-28,30]$, whereas the alanine is crucial for D3 site activity. Indeed, findings of Iwasaki et al. supported this hypothesis [24], since they observed pronounced activity of Ci-VSP(G365A) toward $\mathrm{PI}(3,4) \mathrm{P}_{2}$ in in vitro assays using isolated catalytic domains.

Upon activation of $\mathrm{Ci}-\mathrm{VSP}(\mathrm{G} 365 \mathrm{~A})$ and $\mathrm{Hs}-$ $\mathrm{VSP}_{\mathrm{CiV}}(\mathrm{G} 322 \mathrm{~A})$, we detected a reliable increase in TAPP1PH-GFP binding to the membrane indicating pre-dominant D5 site activity toward $\mathrm{PI}(3,4,5) \mathrm{P}_{3}$ and comparably low activity toward $\mathrm{PI}(3,4) \mathrm{P}_{2}$. These findings are in line with previous studies by Kurokawa et al. [26] and Liu et al. [27], who independently characterized Ci-VSP(G365A) with fluorescent PIP probes in Xenopus laevis oocytes. Thus, in vitro results most probably do not represent substrate specificity of VSPs in living cells. 
Additionally, Iwasaki et al. concluded absence of $\mathrm{PI}(4,5) \mathrm{P}_{2}$ activity for Ci-VSP(G365A) based on experiments performed on Xenopus laevis oocytes with two $\mathrm{PI}(4,5) \mathrm{P}_{2}$ reporter systems, GIRK2 (Kir3.2) channels and the GFP-tagged $\mathrm{PLC}_{1}$-PH domain [24]. In contrast, we here demonstrate reduced, but not substantially altered activity of Ci-VSP(G365A) against $\mathrm{PI}(4,5) \mathrm{P}_{2}$. A straightforward explanation for the different results is that the residual activity of this Ci-VSP mutant was too minute to be detectable with the methods employed by Iwasaki et al.: (i) Whereas Iwasaki and colleagues monitored membrane association of $\mathrm{PLC}_{1}$-PH-GFP with confocal microscopy, we used TIRF imaging that is apparently more sensitive for the detection of small changes in membrane-bound fluorescence. (ii) Iwasaki et al. used a holding potential of $0 \mathrm{mV}$ to activate Ci-VSP, whereas we applied $+80 \mathrm{mV}$ resulting in stronger activation of Ci-VSP. Indeed, we showed earlier [25] that activation of Ci-VSP at $0 \mathrm{mV}$ caused markedly less decrease in membrane binding of the $\mathrm{PLC}_{1}-\mathrm{PH}$ probe than activation at $+80 \mathrm{mV}$ (approximately $10 \mathrm{vs.} 80 \%$ of maximal effect). (iii) Given their low PI(4,5) $\mathrm{P}_{2}$ affinity, KCNQ2 $\left(\mathrm{K}_{\mathrm{v}} 7.2\right)$ channels are highly sensitive to $\mathrm{PI}(4,5) \mathrm{P}_{2}$ depletion [56]. Thus, KCNQ2 channels most probably constitute more sensitive $\mathrm{PI}(4,5) \mathrm{P}_{2}$ sensors than GIRK2 channels utilized by Iwasaki et al.. This sensitivity is reflected in the work by Rjasanow et al. [49] showing that KCNQ2 currents were reduced by about $50 \%$ when Ci-VSP was activated at a holding potential of $-20 \mathrm{mV}$ compared to members of the GIRK channel family that needed $+10 \mathrm{mV}$ (Kir1.1) to $+30 \mathrm{mV}$ (Kir2.1) for comparative inhibition. Thus, GIRK2 channels might be too insensitive to detect the minute $\mathrm{PI}(4,5) \mathrm{P}_{2}$ depletion that is caused by $\mathrm{Ci}-\mathrm{VSP}(\mathrm{G} 365 \mathrm{~A})$ at $0 \mathrm{mV}$.

In summary, we conclude that the glycine-to-alanine exchange in the P loop does not convert VSPs into D3 site specific phosphatases, but attenuates their pre-dominant D5 site activity. It can be speculated that the bulkier side chain of alanine reduces the size of the substrate binding pocket in the VSP(G/A) mutants and, therefore, hampers PI substrate docking into the active site.

\section{The role of the ET pair for determining substrate specificity of VSPs}

Given significant variations in sequence and length between PTEN and VSPs (Fig. S1), the TI/gating loop might determine substrate specificity of the phosphatases. Crystallographic data of the cytosolic fragment of Ci-VSP [27, 34], and molecular dynamics simulations of the full-length $\mathrm{Ci}$ VSP protein with its voltage sensor embedded in a lipid bilayer [36] suggested that this gating loop may adopt different conformations, with the glutamate in the ET pair changing its position to open or close the active site [27]. However, results obtained with Ci-VSP(E411) mutants are

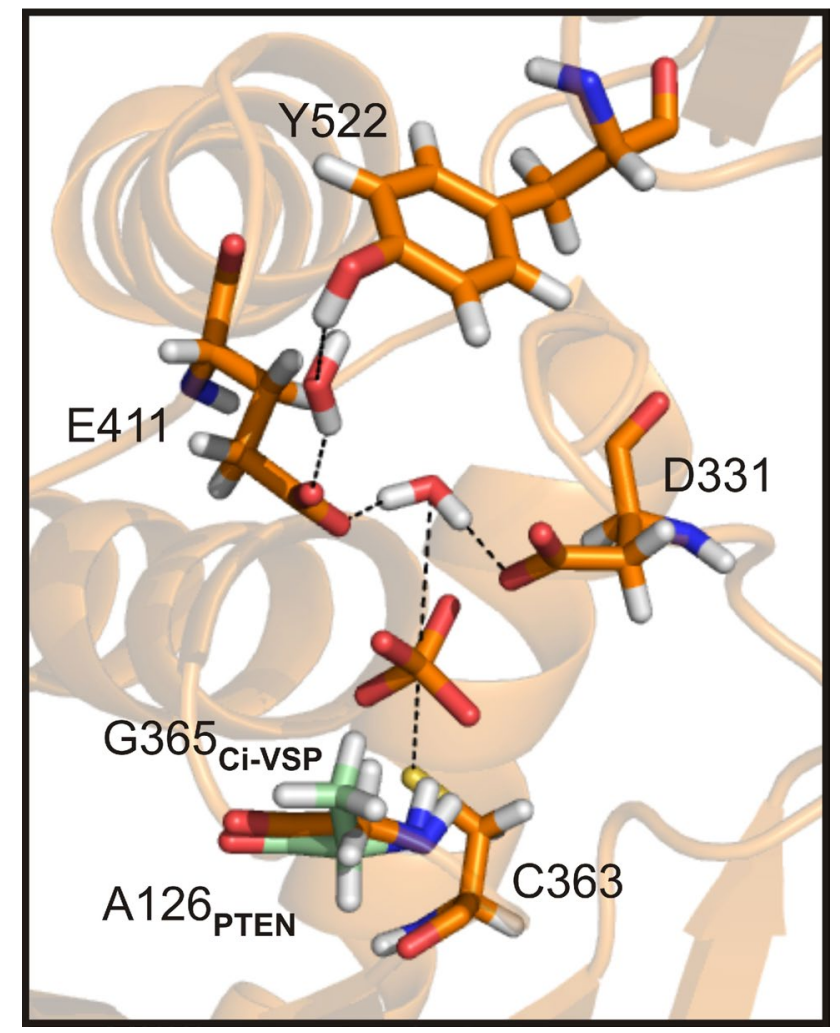

Fig. 5 Hydrogen bonds in the substrate binding pocket of Ci-VSP. View into the substrate binding pocket of Ci-VSP. Residues are depicted as sticks: C363 and G365 in the active site motif/P loop, D331 in the WPD loop, E411 in the gating loop, and Y522 in the CBR3-loop of the C2-domain. The structure of Ci-VSP was obtained by MD simulation as described before $[31,36]$. Structural alignment of the Ci-VSP-model with the 3D-structure of PTEN (PDB 1d5r, [32]) revealed the position of A126 (in green) being homologous to G365 in Ci-VSP. Hydrogen bonds to water molecules and a phosphate ion in the active site are indicated as black dotted lines

inconsistent. Using isolated cytosolic fragments in a malachite green-based phosphatase assay in vitro, Matsuda et al. observed no significant differences in phosphatase activity and substrate specificity between wild type Ci-VSP and E411 mutants, carrying either hydrophobic (E411A) or polar mutations (E411Q and E411T) [34]. In contrast, Liu et al. detected an increase in D5 site activity of Ci-VSP(E411T) toward $\mathrm{PI}(3,4,5) \mathrm{P}_{3}$ using confocal microscopy on Xenopus laevis oocytes which co-expressed full-length Ci-VSP together with the PI $(3,4) \mathrm{P}_{2}$ sensor TAPP1-PH-GFP [27].

Interestingly, Liu et al. described that insertion of hydrophobic residues at position E411 (Ile, Leu, or Phe) reduced phosphatase activity of Ci-VSP toward $\mathrm{PI}(3,4,5) \mathrm{P}_{3}$ and $\mathrm{PI}(4,5) \mathrm{P}_{2}$, whereas hydrophilic side-chains (Asn, Gln, or Thr) were more tolerable for phosphatase activity [27]. Fully in line with our results on ET/TI mutants, Liu et al. suggested that the hydrophilic character of the E411 side chain was important to maintain enzymatic activity of VSPs. As 
proposed earlier [31], the glutamate at position E411 in the ET pair in the gating loop might directly participate in the catalytic reaction of Ci-VSP by forming hydrogen bonds to the water molecule required for substrate hydrolysis (Fig. 5). Such a network of hydrogen bonds was already described for several members of the PTP superfamily (e.g., PTP1B [57, $58]$ and YopH [59, 60]). Mutating the ET pair of VSPs to the less charged TI motif putatively destabilizes these hydrogen bonds in the substrate binding pocket and, therefore, causes the reduction in phosphatase activity. Even more, in the VSP triple-mutants, the impaired electrostatic interactions of the ET/TI pair could be further accompanied by the spatial constraints introduced with the G/A mutation in the $\mathrm{P}$ loop (Fig. 5), leading to the dramatic reduction in phosphatase activity.

\section{Different results of PTEN $\mathrm{Civ}_{\text {and }}$ aSPs provide insight into structures crucial for phosphatase activity in VSPs}

Why is PTEN's substrate specificity readily changed by three simple point mutations, whereas Ci-VSP and Hs-VSP1 ${ }_{\mathrm{CiV}}$ were immune to the reciprocal mutations? A straightforward answer to this question is that certain intramolecular structures may contribute to the substrate binding pocket in native VSPs that are absent or different in PTEN. But what additional structural features could determine the substrate specificity in VSPs?

Taking 3D structures of PTEN [32, 33] and Ci-VSP [27, 34] into account, the major structural difference between these phosphatases is the orientation of the CBR3 loop in the $\mathrm{C} 2$ domain (Fig. 1c), with a tyrosine at position 522 (Y522) pointing into the substrate binding pocket in Ci-VSP. This tyrosine is well-conserved among VSPs, but missing in PTEN (Fig. S1). Previous studies on Ci-VSP suggested a catalytic role for Y522 [27, 28], because mutating it into phenylalanine qualitatively preserved substrate specificity of Ci-VSP, but shifted the apparent voltage dependence of phosphatase activity to depolarized potentials. Because voltage-clamp fluorometry further showed a shift in voltage dependence of voltage sensor motion to higher voltages, Castle et al. suggested that the Y522F-mutation increases the energy barrier of the protein for entering the catalytic cycle [28]. Along these lines, it can be speculated that the mutations we introduced here in VSPs might interfere with steric constraints imposed by the tyrosine in the CBR3 loop and, therefore, prohibit proper substrate binding and hydrolysis. MD simulations on Ci-VSP $[31,36]$ indeed predict interactions between E411 and Y522 through sharing hydrogen bonds to the same water molecule (Fig. 5). Since these interactions might stabilize the position of E411 in the substrate binding pocket, the CBR3 loop could act as an additional structure that influences substrate specificity in VSPs. However, preliminary data demonstrated that activation of Ci-VSP(Y522A) also results in $\mathrm{PI}(3,4) \mathrm{P}_{2}$ accumulation at the membrane, reproducing wild type activity (Fig. S4). Introducing this mutation in the inactive triple mutant of Ci-VSP neither rescued D5 site activity toward $\mathrm{PI}(3,4,5) \mathrm{P}_{3}$ nor induced PTEN-like D3 site activity toward $\mathrm{PI}(3,4) \mathrm{P}_{2}$ in Ci-VSP (Fig. S4). Therefore, distinct effects of TI/ET mutations on the phosphatase activity of PTEN and VSPs cannot be explained by the contribution of the CBR3 loop tyrosine to the substrate binding pocket in VSPs. Unfortunately, no structural data exist so far about PTEN or VSPs with a PI substrate molecule that is bound to the active site. Thus, further effort is needed to reveal the orientation of single residues in the active site that explain the differences in substrate specificity between PTEN and VSPs.

\section{Implications for the role of PTEN as tumor suppressor}

PTEN is one of the most frequently disrupted tumor suppressors in cancer $[6,8,9]$ highlighting that, in most cases, loss-of-function mutations of PTEN contribute to tumor genesis and development of cancer. Recently, we identified an alanine-to-glycine mutation in the active site of PTEN in a prostate tumor sample of a cancer patient [35]. Using a similar approach as presented here, we demonstrated that this mutation induced a gain-of-function of phosphatase activity, converting PTEN from a $\mathrm{PI}(3,4,5) \mathrm{P}_{3}$ D3 phosphatase into a D5 phosphatase. This alteration of enzymatic specificity caused an oncogenic increase in $\mathrm{PI}(3,4) \mathrm{P}_{2}$ levels thereby potentially affecting tumor migration and metastasis. In the present study, we provide additional evidence for conversion of PTEN's site-specific activity through seemingly minor amino acid exchanges in the substrate binding pocket. Therefore, other PTEN mutations may also exhibit oncogenic potential through similar or distinct gain-of-function. Different functional outcomes in terms of catalytic activity may promote tumor genesis or progression through diverging molecular mechanisms, which should be considered in thinking toward prospective PTEN-targeted, patient-specific therapy. Along these lines, the characterization of substrate specificity of tumor-specific PTEN mutants in living cells seems prudent. To this end, employing engineered voltagegated PTEN chimeras may provide a useful strategy. It should be mentioned here, that we have recently presented a technically simplified approach that is easily scalable and, therefore, may be suitable for testing mutant-specific pharmacological interventions [35, 37, 42]. In particular, the PTEN $_{\mathrm{CiV}}$-mutants A126G and TI167/168ET, we described here, might be helpful enzymatic machineries for studies on particular PI-associated pathways, since they allow for manipulation of $\mathrm{PI}(3,4,5) \mathrm{P}_{3}$ while producing $\mathrm{PI}(3,4) \mathrm{P}_{2}$ without disturbing membrane $\mathrm{PI}(4,5) \mathrm{P}_{2}$ levels. Presumably, 
more advanced knowledge of the determinants of the substrate specificity might enable the design of voltage-sensitive phosphatases with desirable substrate specificities expanding their applicability for studies on PI signaling.

Acknowledgements The authors gratefully acknowledge the gifts of plasmids for Ci-VSP from Y. Okamura, for $\mathrm{PLC}_{1}-\mathrm{PH}$ and Btk-PH, from T. Balla, for TAPP1-PH from D. Alessi, for PI3K from J. Downward and for KCNQ2 from T. Jentsch. We also thank C.D. Bustamante for providing PC-3 cells. Gratefully, we thank the core facility "Flow cytometry" and H. Raifer at the Philipps-University Marburg for technical support in FACS-experiments. We further thank T. Utesch for his support regarding protein structures and dynamics. We are very much obliged to O. Ebers, R. Enzeroth, and G. Fischer for expert technical assistance.

Author contributions MGL, KH, DO and CRH conceived the study. MGL, KH, AM, AF, and CRH planned and performed experiments and analyzed data. $\mathrm{KH}$ provided MD simulation data to the discussion section. JO supervised TIRF-/patch clamp recordings. MGL, KH, DO, and $\mathrm{CRH}$ wrote the manuscript. All authors read and approved the final version of the manuscript. All experiments were conducted at the Institute of Physiology and Pathophysiology at the Philipps-University Marburg (Germany).

Funding This work was supported by the Research Grants of the University Medical Center Giessen and Marburg given to M.G.L. (UKGM 13/2016MR) and to C.R.H. (UKGM 32/2011MR) and by a Grant of Deutsche Forschungsgemeinschaft to D.O. (DFG Research Training Group GRK 2213).

\section{Compliance with ethical standards}

Conflict of interest The authors have no conflict of interest to declare.

Data and materials availability All data generated and analyzed during this study are included in this published article and its supplementary information files.

Open Access This article is distributed under the terms of the Creative Commons Attribution 4.0 International License (http://creativeco mmons.org/licenses/by/4.0/), which permits unrestricted use, distribution, and reproduction in any medium, provided you give appropriate credit to the original author(s) and the source, provide a link to the Creative Commons license, and indicate if changes were made.

\section{References}

1. Myers MP, Pass I, Batty IH et al (1998) The lipid phosphatase activity of PTEN is critical for its tumor suppressor function. Proc Natl Acad Sci USA 95:13513-13518. https://doi.org/10.1073/ pnas.95.23.13513

2. Maehama T, Dixon JE (1998) The tumor suppressor, PTEN/ MMAC1, dephosphorylates the lipid second messenger, phosphatidylinositol 3,4,5-trisphosphate. J Biol Chem 273:13375-13378

3. McConnachie G, Pass I, Walker SM, Downes CP (2003) Interfacial kinetic analysis of the tumour suppressor phosphatase, PTEN: evidence for activation by anionic phospholipids. Biochem J 371:947-955. https://doi.org/10.1042/BJ20021848
4. Wei Y, Stec B, Redfield AG et al (2015) Phospholipid-binding sites of phosphatase and tensin homolog (PTEN). J Biol Chem 290:1592-1606. https://doi.org/10.1074/jbc.M114.588590

5. Malek M, Kielkowska A, Chessa T et al (2017) PTEN regulates PI $(3,4) \mathrm{P} 2$ signaling downstream of class I PI3K. Mol Cell 68(566-580):e10. https://doi.org/10.1016/j.molcel.2017.09.024

6. Rodríguez-Escudero I, Oliver MD, Andrés-Pons A et al (2011) A comprehensive functional analysis of PTEN mutations: implications in tumor- and autism-related syndromes. Hum Mol Genet 20:4132-4142. https://doi.org/10.1093/hmg/ddr337

7. Steck PA, Pershouse MA, Jasser SA et al (1997) Identification of a candidate tumour suppressor gene, MMAC1, at chromosome $10 q 23.3$ that is mutated in multiple advanced cancers. Nat Genet 15:356-362. https://doi.org/10.1038/ng0497-356

8. Liu Y, Bankaitis VA (2010) Phosphoinositide phosphatases in cell biology and disease. Prog Lipid Res 49:201-217. https://doi. org/10.1016/j.plipres.2009.12.001

9. Stebbing J, Lit L, Zhang $\mathrm{H}$ et al (2014) The regulatory roles of phosphatases in cancer. Oncogene 33:939-953. https://doi. org/10.1038/onc.2013.80

10. Pun RYK, Rolle IJ, LaSarge CL et al (2012) Excessive activation of mTOR in postnatally generated granule cells is sufficient to cause epilepsy. Neuron 75:1022-1034. https://doi.org/10.1016/j. neuron.2012.08.002

11. Butler MG (2005) Subset of individuals with autism spectrum disorders and extreme macrocephaly associated with germline PTEN tumour suppressor gene mutations. J Med Genet 42:318-321. https://doi.org/10.1136/jmg.2004.024646

12. Zhou J, Parada LF (2012) PTEN signaling in autism spectrum disorders. Curr Opin Neurobiol 22:873-879. https://doi. org/10.1016/j.conb.2012.05.004

13. O'Roak BJ, Vives L, Fu W et al (2012) Multiplex targeted sequencing identifies recurrently mutated genes in autism spectrum disorders. Science (80-) 338:1619-1622. https://doi. org/10.1126/science.1227764

14. Hobert JA, Embacher R, Mester JL et al (2014) Biochemical screening and PTEN mutation analysis in individuals with autism spectrum disorders and macrocephaly. Eur J Hum Genet 22:273276. https://doi.org/10.1038/ejhg.2013.114

15. Tilot AK, Frazier TW, Eng C (2015) Balancing proliferation and connectivity in PTEN-associated autism spectrum disorder. Neurotherapeutics 12:609-619. https://doi.org/10.1007/s1331 1-015-0356-8

16. Knafo S, Sánchez-Puelles C, Palomer E et al (2016) PTEN recruitment controls synaptic and cognitive function in Alzheimer's models. Nat Neurosci 19:443-453. https://doi.org/10.1038/ nn. 4225

17. Frere S, Slutsky I (2016) Targeting PTEN interactions for Alzheimer's disease. Nat Neurosci 19:416-418. https://doi.org/10.1038/ nn. 4248

18. Murata Y, Iwasaki H, Sasaki M et al (2005) Phosphoinositide phosphatase activity coupled to an intrinsic voltage sensor. Nature 435:1239-1243. https://doi.org/10.1038/nature03650

19. Hossain MI, Iwasaki H, Okochi Y et al (2008) Enzyme domain affects the movement of the voltage sensor in ascidian and zebrafish voltage-sensing phosphatases. J Biol Chem 283:18248 18259. https://doi.org/10.1074/jbc.M706184200

20. Ratzan WJ, Evsikov AV, Okamura Y, Jaffe LA (2011) Voltage sensitive phosphoinositide phosphatases of Xenopus: their tissue distribution and voltage dependence. J Cell Physiol 226:2740-2746. https://doi.org/10.1002/jcp.22854

21. Walker SM, Downes CP, Leslie NR (2001) TPIP: a novel phosphoinositide 3-phosphatase. Biochem J 360:277-283

22. Tapparel C, Reymond A, Girardet C et al (2003) The TPTE gene family: cellular expression, subcellular localization and alternative splicing. Gene 323:189-199 
23. Halaszovich CR, Leitner MG, Mavrantoni A et al (2012) A human phospholipid phosphatase activated by a transmembrane control module. J Lipid Res 53:2266-2274. https://doi.org/10.1194/jlr. M026021

24. Iwasaki H, Murata Y, Kim Y et al (2008) A voltage-sensing phosphatase, Ci-VSP, which shares sequence identity with PTEN, dephosphorylates phosphatidylinositol 4,5-bisphosphate. Proc Natl Acad Sci USA 105:7970-7975. https://doi.org/10.1073/ pnas.0803936105

25. Halaszovich CR, Schreiber DN, Oliver D (2009) Ci-VSP is a depolarization-activated phosphatidylinositol-4,5-bisphosphate and phosphatidylinositol-3,4,5-trisphosphate 5'-phosphatase. J Biol Chem 284:2106-2113. https://doi.org/10.1074/jbc.M8035 43200

26. Kurokawa T, Takasuga S, Sakata S et al (2012) 3' Phosphatase activity toward phosphatidylinositol 3,4-bisphosphate [PI(3,4)P2] by voltage-sensing phosphatase (VSP). Proc Natl Acad Sci USA 109:10089-10094. https://doi.org/10.1073/pnas.1203799109

27. Liu L, Kohout SC, Xu Q et al (2012) A glutamate switch controls voltage-sensitive phosphatase function. Nat Struct Mol Biol 19:633641. https://doi.org/10.1038/nsmb.2289

28. Castle PM, Zolman KD, Kohout SC (2015) Voltage-sensing phosphatase modulation by a C2 domain. Front Pharmacol 6:1-15. https ://doi.org/10.3389/fphar.2015.00063

29. Grimm SS, Isacoff EY (2016) Allosteric substrate switching in a voltage-sensing lipid phosphatase. Nat Chem Biol 12:261-267. https ://doi.org/10.1038/nchembio.2022

30. Keum D, Kruse M, Kim D-I et al (2016) Phosphoinositide 5- and 3 -phosphatase activities of a voltage-sensing phosphatase in living cells show identical voltage dependence. Proc Natl Acad Sci. https ://doi.org/10.1073/pnas.1606472113

31. Hobiger K, Friedrich T (2015) Voltage sensitive phosphatases: emerging kinship to protein tyrosine phosphatases from structurefunction research. Front Pharmacol 6:1-19. https://doi.org/10.3389/ fphar.2015.00020

32. Lee JO, Yang H, Georgescu MM et al (1999) Crystal structure of the PTEN tumor suppressor: implications for its phosphoinositide phosphatase activity and membrane association. Cell 99:323-334

33. Lee C-U, Hahne G, Hanske J et al (2015) Redox modulation of PTEN phosphatase activity by hydrogen peroxide and bisperoxidovanadium complexes. Angew Chemie Int Ed 54:13796-13800. https ://doi.org/10.1002/anie.201506338

34. Matsuda M, Takeshita K, Kurokawa T et al (2011) Crystal structure of the cytoplasmic phosphatase and tensin homolog (PTEN)-like region of Ciona intestinalis voltage-sensing phosphatase provides insight into substrate specificity and redox regulation of the phosphoinositide phosphatase activity. J Biol Chem 286:23368-23377. https://doi.org/10.1074/jbc.M110.214361

35. Costa HA, Leitner MG, Sos ML et al (2015) Discovery and functional characterization of a neomorphic PTEN mutation. Proc Natl Acad Sci 112:13976-13981. https://doi.org/10.1073/pnas.14225 04112

36. Hobiger K, Utesch T, Mroginski MA et al (2013) The linker pivot in Ci-VSP: the key to unlock catalysis. PLoS One 8:e70272. https:// doi.org/10.1371/journal.pone.0070272

37. Lacroix JJ, Halaszovich CR, Schreiber DN et al (2011) Controlling the activity of a phosphatase and tensin homolog (PTEN) by membrane potential. J Biol Chem 286:17945-17953. https://doi. org/10.1074/jbc.M110.201749

38. Rodriguez-Viciana P, Warne PH, Vanhaesebroeck B et al (1996) Activation of phosphoinositide 3-kinase by interaction with Ras and by point mutation. EMBO J 15:2442-2451

39. Edelstein AD, Tsuchida MA, Amodaj N et al (2014) Advanced methods of microscope control using $\mu$ Manager software. J Biol Methods 1:10. https://doi.org/10.14440/jbm.2014.36
40. Schneider CA, Rasband WS, Eliceiri KW (2012) NIH Image to ImageJ: 25 years of image analysis. Nat Methods 9:671-675

41. Schindelin J, Arganda-Carreras I, Frise E et al (2012) Fiji: an opensource platform for biological-image analysis. Nat Methods 9:676682. https://doi.org/10.1038/nmeth.2019

42. Mavrantoni A, Thallmair V, Leitner MG et al (2015) A method to control phosphoinositides and to analyze PTEN function in living cells using voltage sensitive phosphatases. Front Pharmacol 6:1-13. https://doi.org/10.3389/fphar.2015.00068

43. Rothman KJ (1990) No adjustments are needed for multiple comparisons. Epidemiology 1:43-46

44. Salim K, Bottomley MJ, Querfurth E et al (1996) Distinct specificity in the recognition of phosphoinositides by the pleckstrin homology domains of dynamin and Bruton's tyrosine kinase. EMBO J 15:6241-6250

45. Várnai P, Rother KI, Balla T (1999) Phosphatidylinositol 3-kinasedependent membrane association of the Bruton's tyrosine kinase pleckstrin homology domain visualized in single living cells. J Biol Chem 274:10983-10989

46. Kimber WA, Trinkle-Mulcahy L, Cheung PCF et al (2002) Evidence that the tandem-pleckstrin-homology-domain-containing protein TAPP1 interacts with Ptd(3,4)P2 and the multi-PDZ-domain-containing protein MUPP1 in vivo. Biochem J 361:525-536

47. Manna D, Albanese A, Park WS, Cho W (2007) Mechanistic basis of differential cellular responses of phosphatidylinositol 3,4-bisphosphate- and phosphatidylinositol 3,4,5-trisphosphate-binding pleckstrin homology domains. J Biol Chem 282:32093-32105. https:// doi.org/10.1074/jbc.M703517200

48. Zhang H, Craciun LC, Mirshahi T et al (2003) PIP(2) activates KCNQ channels, and its hydrolysis underlies receptor-mediated inhibition of M currents. Neuron 37:963-975

49. Rjasanow A, Leitner MG, Thallmair V et al (2015) Ion channel regulation by phosphoinositides analyzed with VSPs-PI(4,5)P2 affinity, phosphoinositide selectivity, and PI(4,5)P2 pool accessibility. Front Pharmacol 6:127. https://doi.org/10.3389/fphar.2015.00127

50. Downes CP, Walker S, McConnachie G et al (2004) Acute regulation of the tumour suppressor phosphatase, PTEN, by anionic lipids and reactive oxygen species. Biochem Soc Trans 32:338-342. https ://doi.org/10.1042/bst0320338

51. Redfern RE, Redfern D, Furgason MLM et al (2008) PTEN phosphatase selectively binds phosphoinositides and undergoes structural changes. Biochemistry 47:2162-2171. https://doi.org/10.1021/bi702 $114 \mathrm{w}$

52. Campbell RB, Liu F, Ross AH (2003) Allosteric activation of PTEN phosphatase by phosphatidylinositol 4,5-bisphosphate. J Biol Chem 278:33617-33620

53. Shenoy S, Shekhar P, Heinrich F et al (2012) Membrane association of the PTEN tumor suppressor: molecular details of the protein-membrane complex from SPR binding studies and neutron reflection. PLoS One 7:e32591. https://doi.org/10.1371/journ al.pone.0032591

54. Shenoy SS, Nanda H, Lösche M (2012) Membrane association of the PTEN tumor suppressor: electrostatic interaction with phosphatidylserine-containing bilayers and regulatory role of the C-terminal tail. J Struct Biol 180:394-408. https://doi.org/10.1016/j.jsb.2012.10.003

55. Liu C, Deb S, Ferreira VS et al (2018) Kinetics of PTEN-mediated $\mathrm{PI}(3,4,5) \mathrm{P} 3$ hydrolysis on solid supported membranes. PLoS One 13:e0192667. https://doi.org/10.1371/journal.pone.0192667

56. Hernandez CC, Zaika O, Shapiro MS (2008) A carboxy-terminal inter-helix linker as the site of phosphatidylinositol 4,5-bisphosphate action on Kv7 (M-type) K+ channels. J Gen Physiol 132:361-381. https://doi.org/10.1085/jgp.200810007

57. Pannifer AD, Flint AJ, Tonks NK, Barford D (1998) Visualization of the cysteinyl-phosphate intermediate of a protein-tyrosine phosphatase by X-ray crystallography. J Biol Chem 273:10454-10462. https://doi.org/10.1074/jbc.273.17.10454 
58. Brandao TAS, Hengge AC, Johnson SJ (2010) Insights into the reaction of protein-tyrosine phosphatase 1B: crystal structures for transition state analogs of both catalytic steps. J Biol Chem 285:1587415883. https://doi.org/10.1074/jbc.M109.066951

59. Zhao Y, Wu L, Noh SJ et al (1998) Altering the nucleophile specificity of a protein-tyrosine phosphatase-catalyzed reaction: probing the function of the invariant glutamine residues. J Biol Chem 273:5484 5492. https://doi.org/10.1074/jbc.273.10.5484

60. Sun J-P, Wu L, Fedorov AA et al (2003) Crystal structure of the Yersinia protein-tyrosine phosphatase YopH complexed with a specific small molecule inhibitor. J Biol Chem 278:33392-33399. https ://doi.org/10.1074/jbc.M304693200 